Supplementary Information

\title{
Helicity Manipulation of a Double Paddled Binaphthyl in Two-Dimensional Matrix Field at the Air-Water Interface
}

Masaki Ishii, a,b Taizo Mori, ${ }^{\mathrm{b}, \mathrm{c}, \mathrm{d} *}$ Waka Nakanishi, ${ }^{\mathrm{b}}$ Jonathan P. Hill, ${ }^{\mathrm{b}}$ Hideki Sakai, ${ }^{a}$ Katsuhiko Ariga ${ }^{b, c *}$

${ }^{a}$ Graduate School of Science and Technology, Tokyo University of Science, 2641 Yamazaki, Noda, Chiba 278-8510, Japan

bInternational Center for Materials Nanoarchitectonics (MANA), National Institute for Materials Science (NIMS), 1-1 Namiki, Tsukuba, Ibaraki 305-0044, Japan

'Graduate School of Frontier Sciences, The University of Tokyo, 5-1-5 Kashiwanoha, Kashiwa, Chiba, 277-8561, Japan

Institute for Solid State Physics, The University of Tokyo, 5-1-5 Kashiwanoha, Kashiwa, Chiba, 2778581, Japan 
(a)

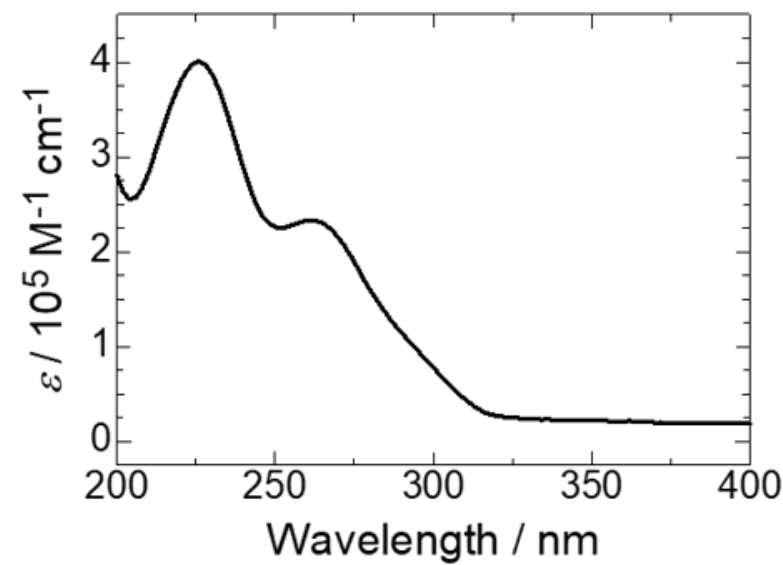

(b)

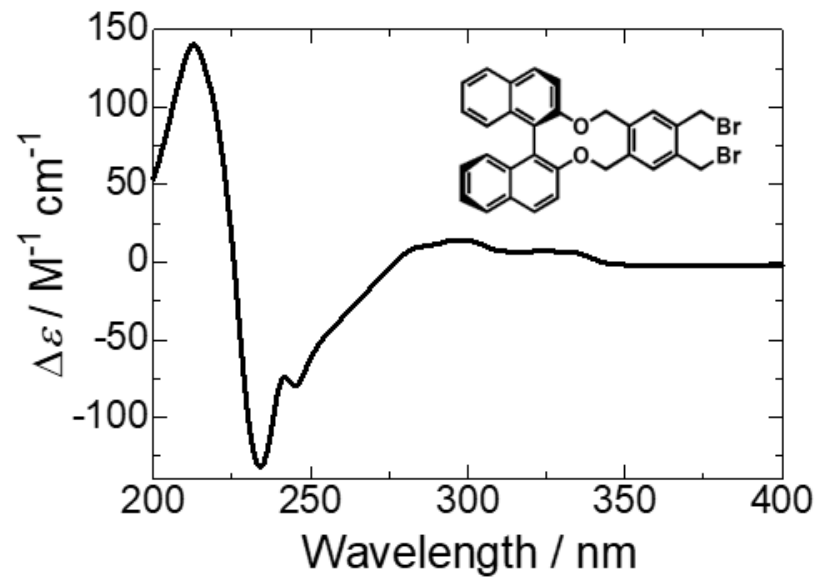

Figure S1. (a) UV-vis absorbance of $\alpha, \alpha^{\prime}, \alpha^{\prime \prime}, \alpha^{\prime \prime \prime}-$ tetrabromodurene in acetonitrile. (b) CD spectrum of monobinaphthyldurene (MBD) in acetonitrile.
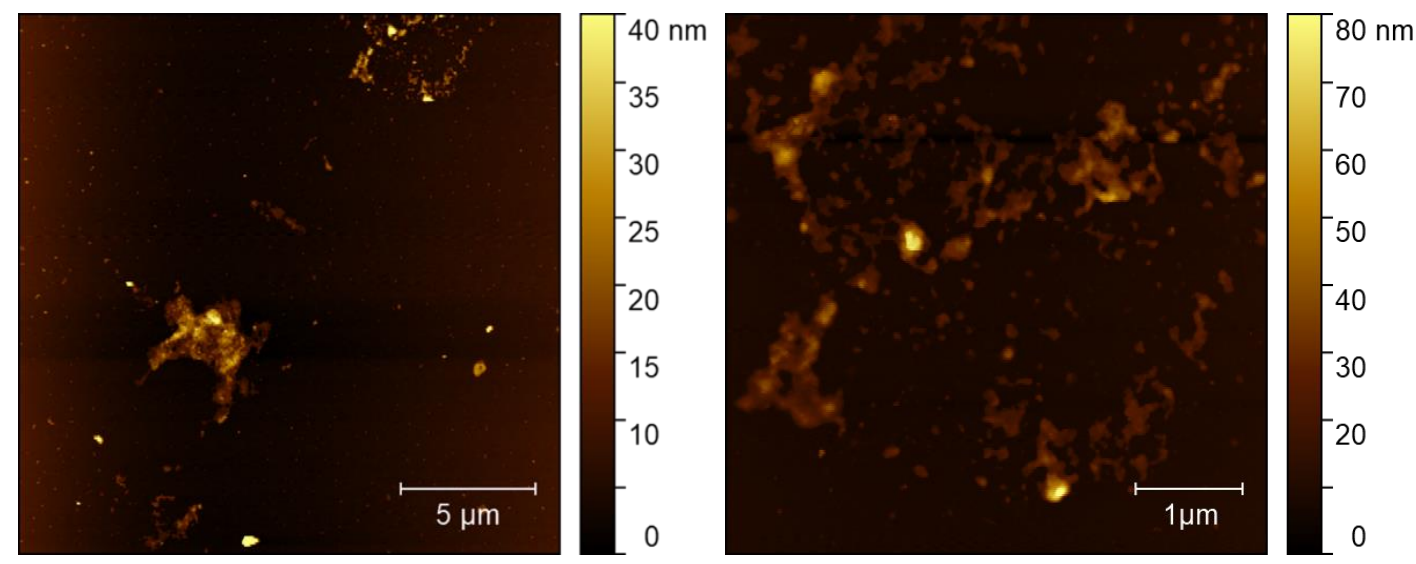

Figure S2. AFM images of BBD film transferred at $40 \mathrm{mN} \mathrm{m}^{-1}$. 


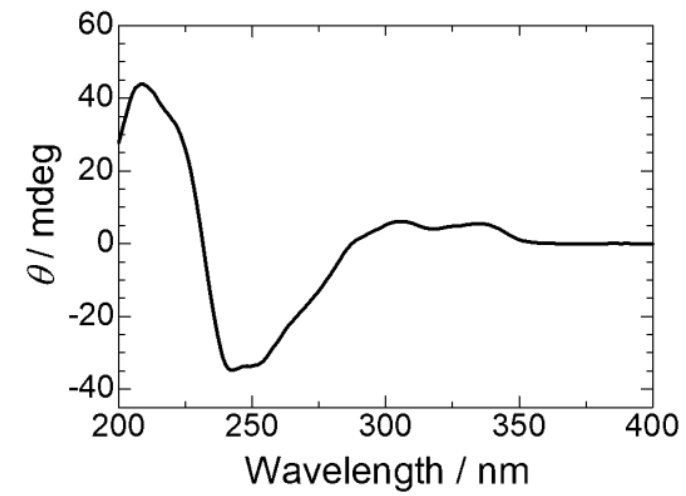

Figure S3. CD spectrum of BBD in acetonitrile/water.

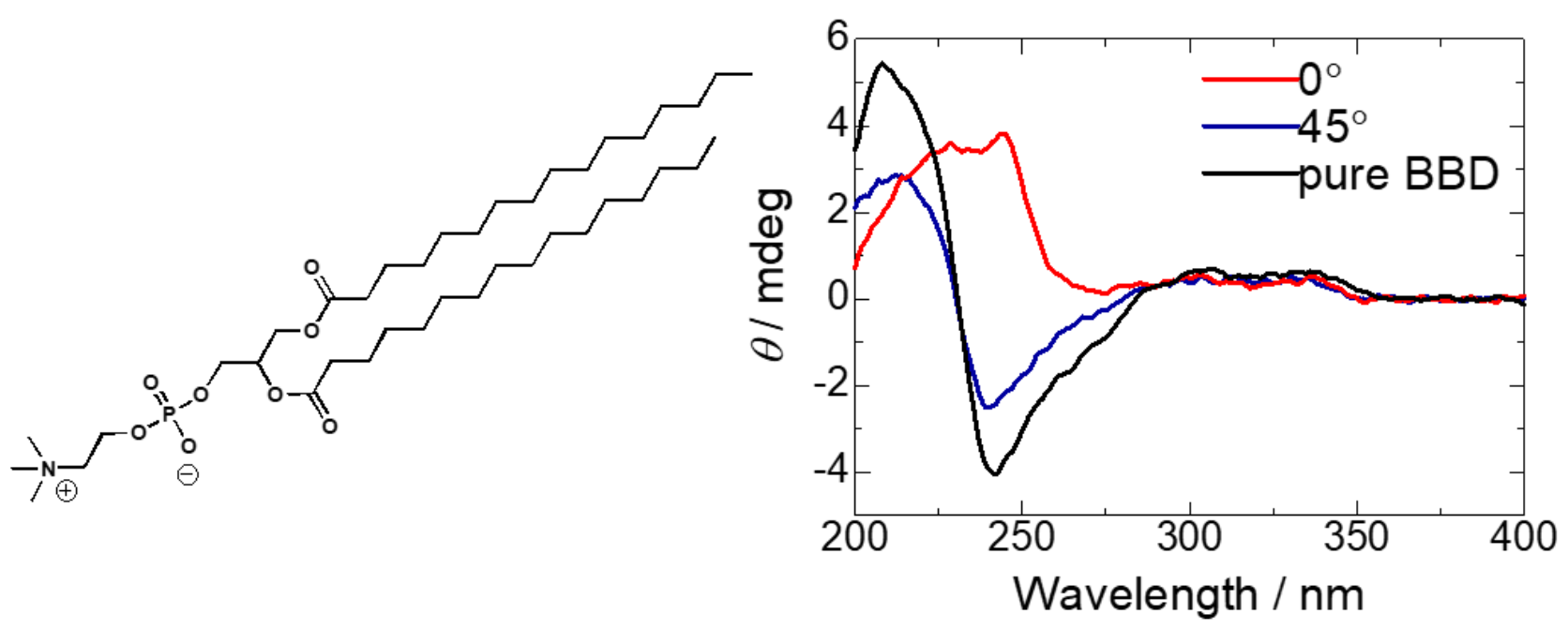

Figure S4. Chemical structures of racemic DPPC and CD spectra of pure BBD and mixed monolayers with rac-DPPC transferred on $41 \mathrm{mN} \mathrm{m}^{-1}$. The film was rotated to the light beam from $0^{\circ}$ to $45^{\circ}$. 
(a)
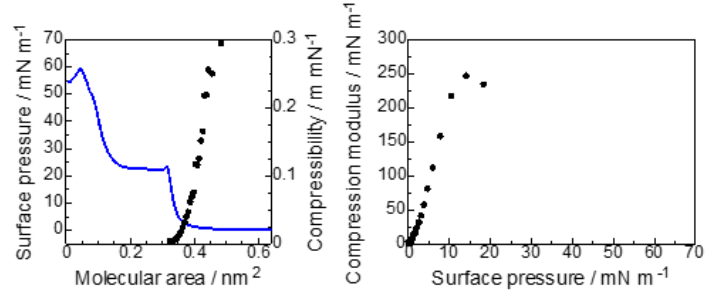

(c)
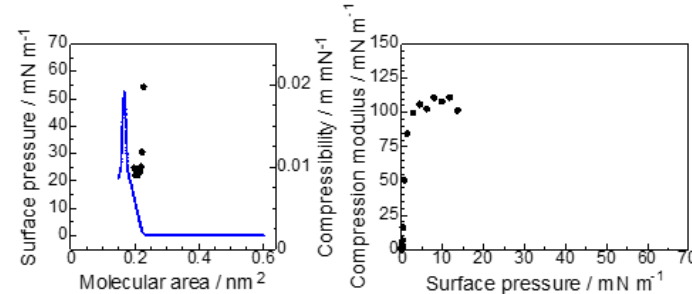

(e)

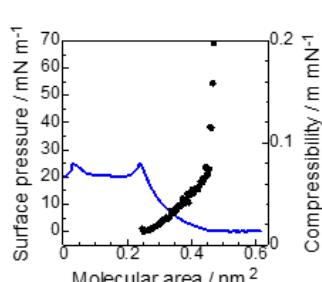

(g)

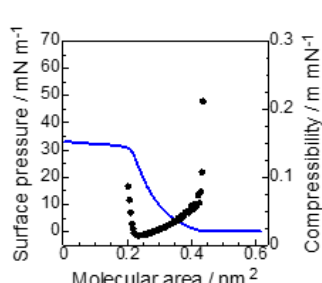

(i)

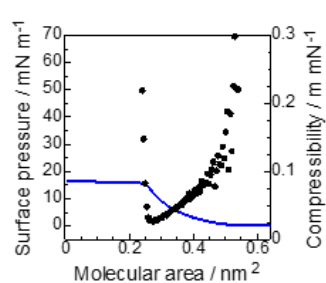

(k)
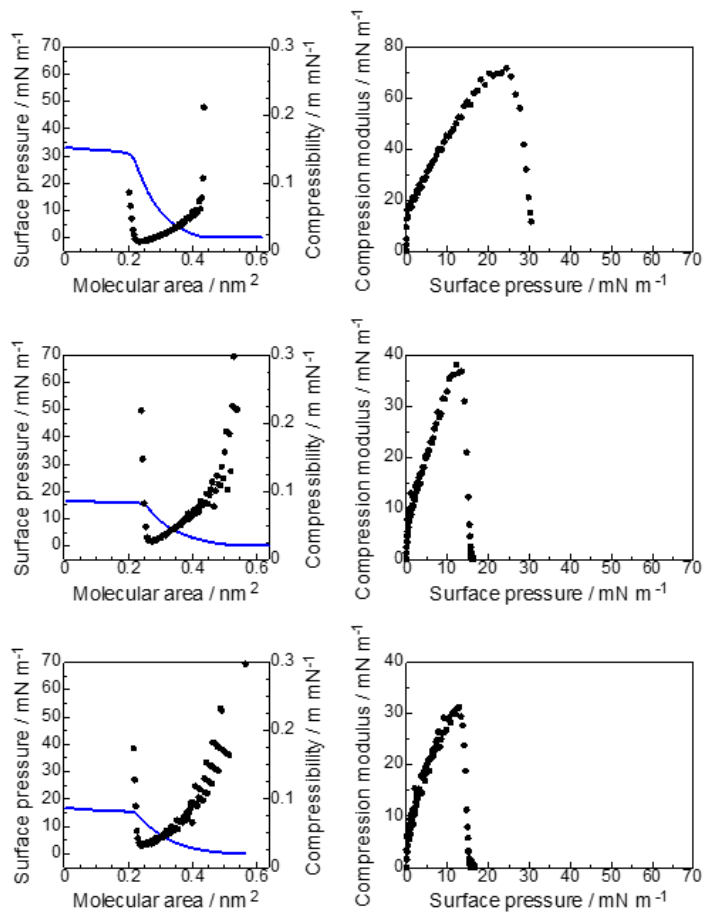

(b)
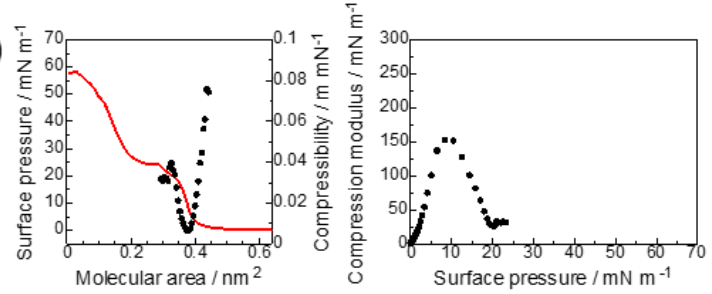

(d)
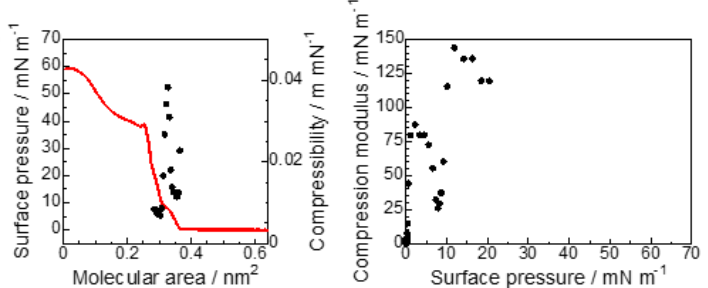

(f)
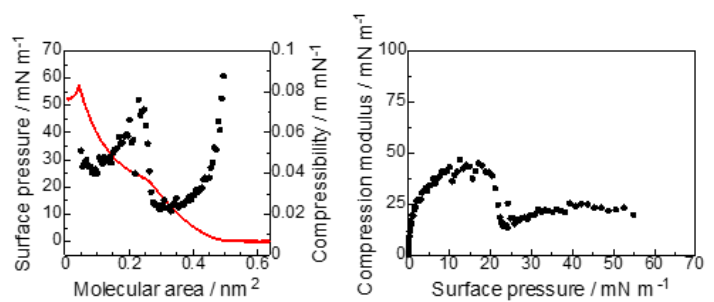

(h)

(j)
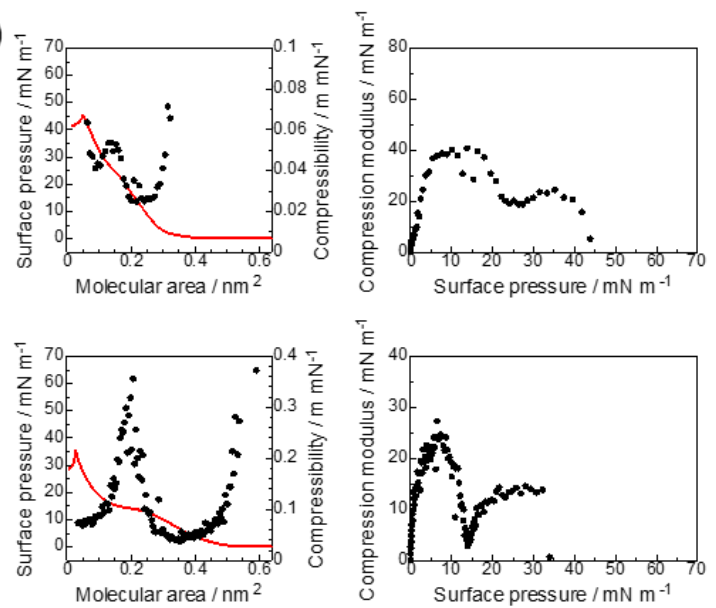

(I)
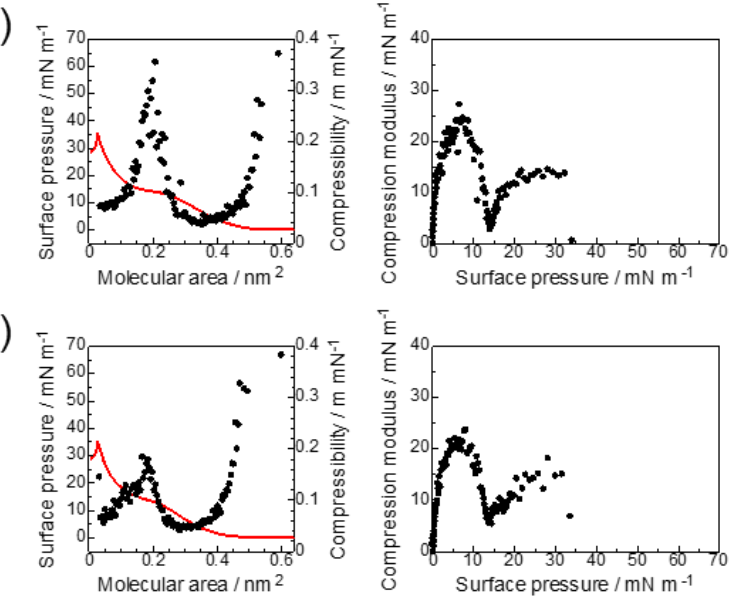

Figure S5. $C_{s}-A$ isotherms of monolayers and the corresponding $\pi-A$ isotherms (shown as blue and red lines). $C s^{-1}-\pi$ curves for the monolayers. (a) CA and (b) BBD with CA, (c) SA and (d) BBD with SA, (e) EA and (f) BBD with EA (g) OA and (h) BBD with OA, (i) ME and (j) BBD with ME, (a) MO and (b) $\mathrm{BBD}$ with $\mathrm{MO}$. BBD/matrix molar ratios are $1 / 2$. 
(a) $\mathrm{CA}, 41 \mathrm{mN} / \mathrm{m}$

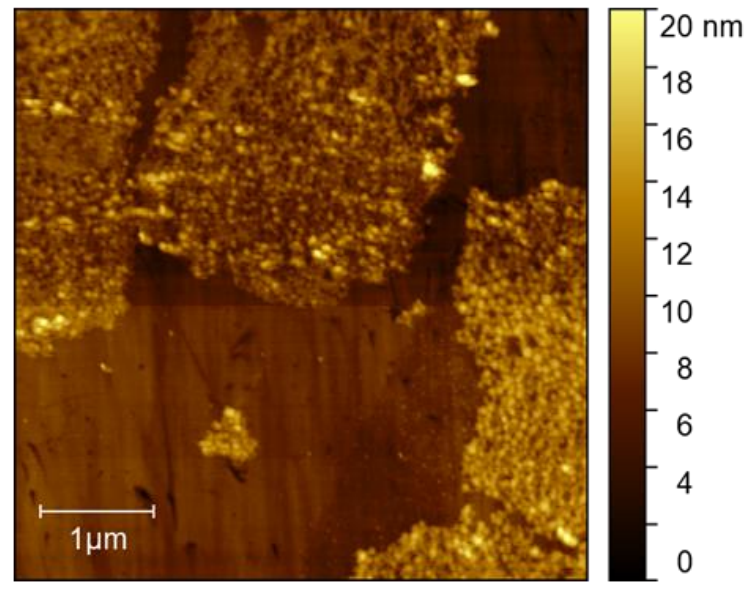

(c) $\mathrm{EA}, 41 \mathrm{mN} / \mathrm{m}$

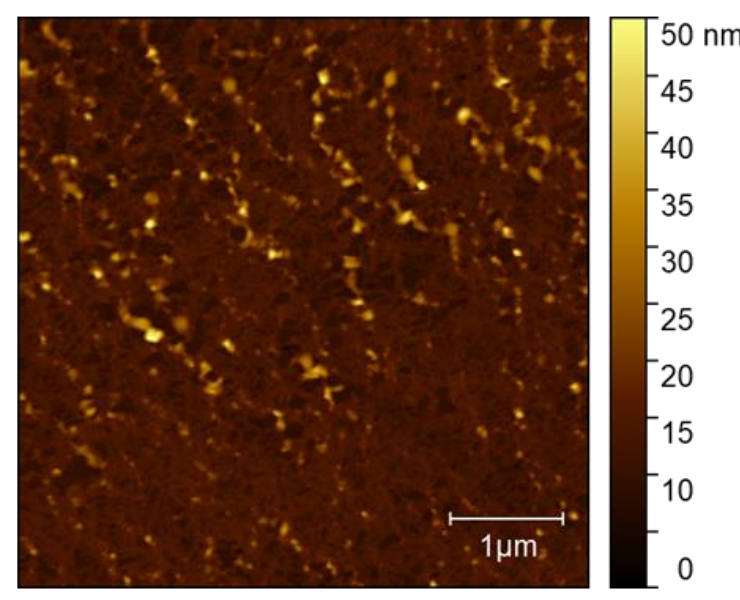

(e) $\mathrm{ME}, 31 \mathrm{mN} / \mathrm{m}$

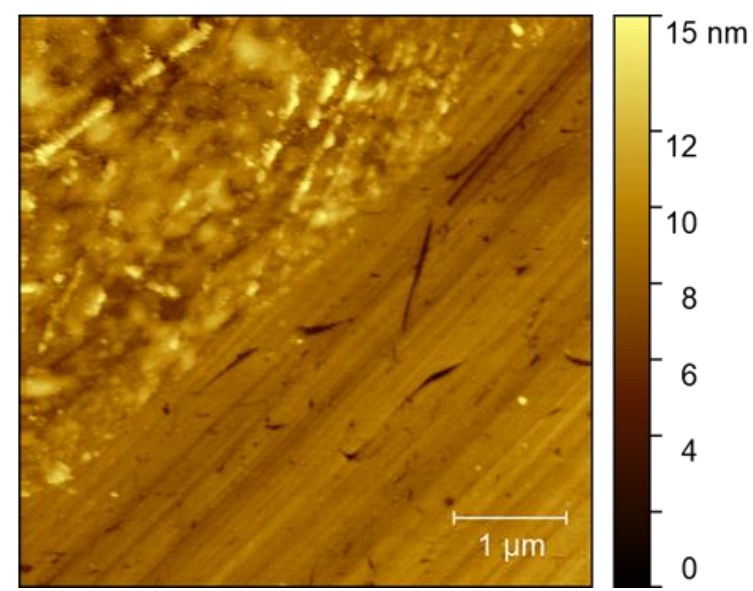

(b) $\mathrm{SA}, 38 \mathrm{mN} / \mathrm{m}$

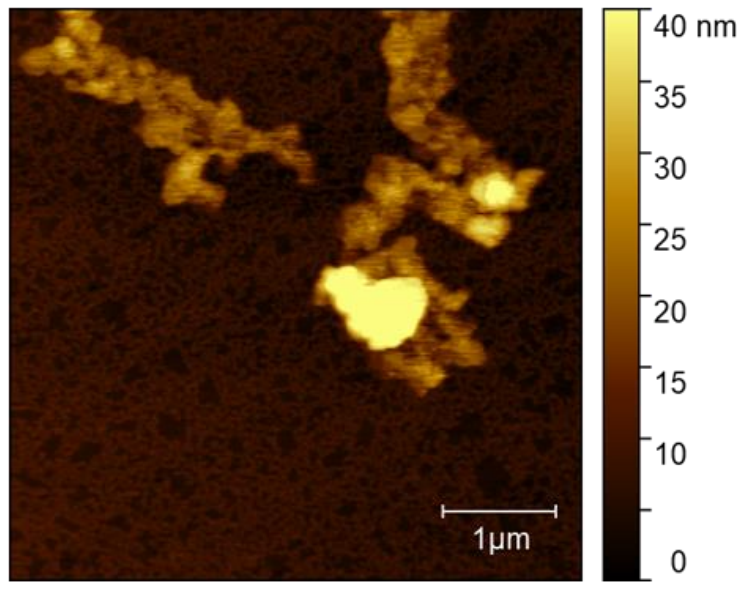

(d) $O A, 41 \mathrm{mN} / \mathrm{m}$

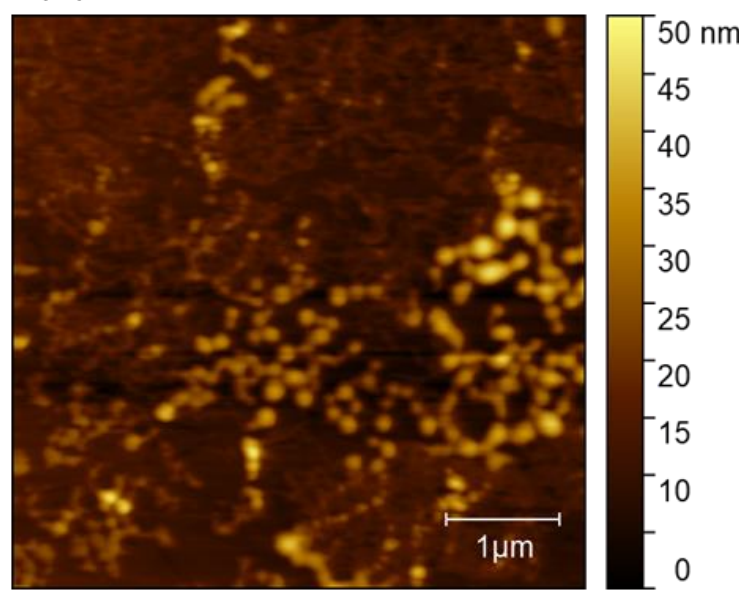

(f) $\mathrm{MO}, 31 \mathrm{mN} / \mathrm{m}$

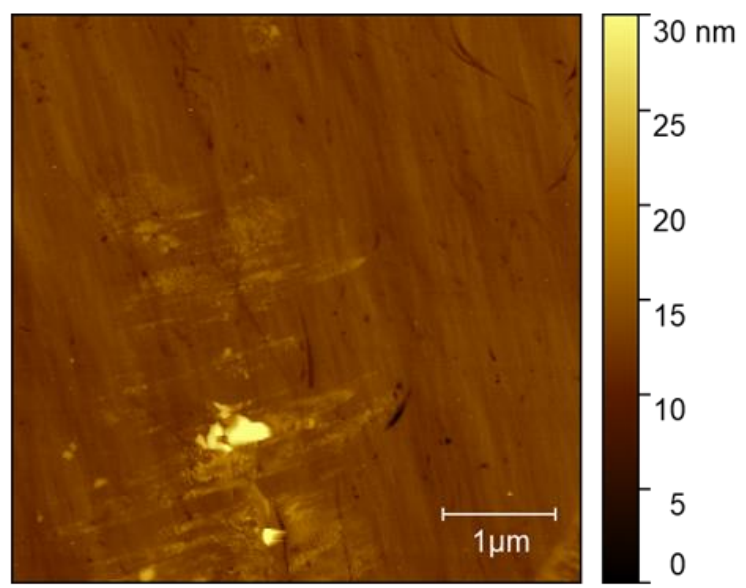

Figure S6. AFM images of BBD mixed monolayer with lipids. (a) cholesteryl acetate (CA), (b) stearic acid (SA), (c) elaidic acid (EA), (d) oleic acid (OA), (e) methyl elaidate (ME) and (f) methyl oleate (MO). $\mathrm{BBD} /$ matrix molar ratios are $1 / 2$. 
(a)

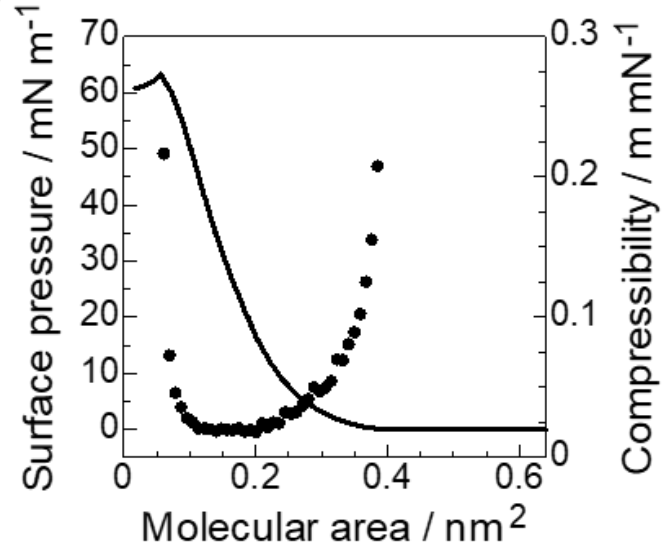

(b) 'َ'

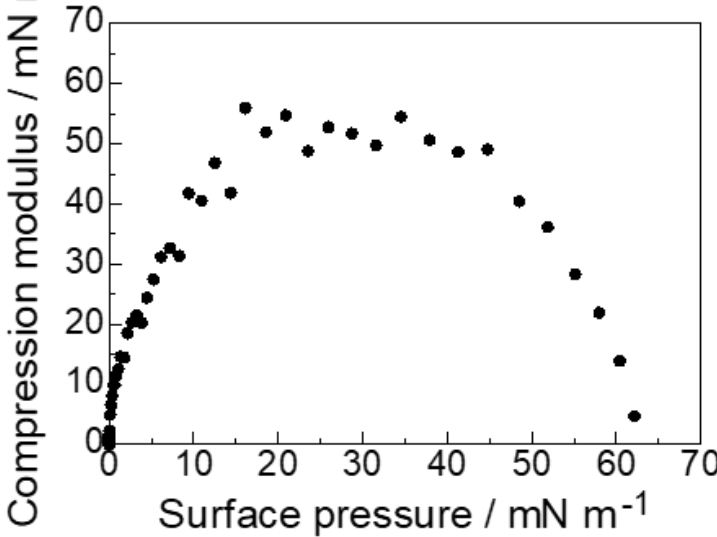

Figure S7. $C_{s}-A$ isotherms of BBD and the corresponding $\pi-A$ isotherms. $C s^{-1}-\pi$ curves for BBD.

Table S1. Maxima of compression modulus of lipids and mixture with BBD.

\begin{tabular}{ccc}
\hline \multirow{2}{*}{ Lipid } & \multicolumn{2}{c}{$\mathrm{Cs}^{-1}{ }_{\max } / \mathrm{mN} \mathrm{m}^{-1}$} \\
& Pure lipid & with BBD \\
\hline CA & 246.5 & 152.5 \\
\hline SA & 111.0 & 143.8 \\
\hline EA & 76.1 & 46.6 \\
\hline OA & 71.6 & 40.7 \\
\hline ME & 38.1 & 27.3 \\
\hline MO & 31.2 & 23.8 \\
\hline
\end{tabular}


Table S2. Portions of CD bands and compression modulus of mixed monolayers.

\begin{tabular}{|c|c|c|c|c|c|c|c|c|}
\hline \multirow{2}{*}{ Sample } & \multirow{2}{*}{$\lambda_{\max } / \mathrm{nm}$} & \multicolumn{6}{|c|}{ Proportion /\% } & \multirow{2}{*}{$\begin{array}{c}\mathrm{Cs}^{-1} \max \\
/ \mathrm{mN} \mathrm{m}^{-1}\end{array}$} \\
\hline & & $240 \mathrm{~nm}$ & $\lambda_{t} / \mathrm{nm}$ & $250 \mathrm{~nm}$ & $\lambda_{t} / \mathrm{nm}$ & $265 \mathrm{~nm}$ & $\lambda_{t} / \mathrm{nm}$ & \\
\hline BBD & 242 & 28.7 & 238 & 48.3 & 248 & 23.0 & 268 & 55.9 \\
\hline$+\mathrm{CA}$ & 240 & 33.0 & 237 & 41.5 & 248 & 25.5 & 266 & 152.5 \\
\hline$+\mathrm{SA}$ & 240 & 21.6 & 238 & 39.4 & 247 & 39.0 & 261 & 143.8 \\
\hline$+E A$ & 252 & 25.6 & 237 & 30.9 & 251 & 43.5 & 263 & 46.6 \\
\hline$+O A$ & 252 & 17.6 & 237 & 22.2 & 252 & 60.2 & 262 & 40.7 \\
\hline$+M E$ & 253 & 19.0 & 236 & 29.4 & 253 & 51.6 & 264 & 27.3 \\
\hline$+\mathrm{MO}$ & 253 & 20.4 & 236 & 27.8 & 252 & 51.8 & 263 & 23.8 \\
\hline \multirow{2}{*}{ Sample } & \multirow{2}{*}{$\lambda_{\max } / \mathrm{nm}$} & \multicolumn{6}{|c|}{ Proportion /\% } & $\mathrm{Cs}^{-1}{ }_{\max }$ \\
\hline & & $305 \mathrm{~nm}$ & $\lambda_{\mathrm{t}} / \mathrm{nm}$ & $325 \mathrm{~nm}$ & $\lambda_{\mathrm{t}} / \mathrm{nm}$ & $340 \mathrm{~nm}$ & $\lambda_{\mathrm{t}} / \mathrm{nm}$ & $/ \mathrm{mN} \mathrm{m}^{-1}$ \\
\hline BBD & 242 & 61.8 & 305 & 1.4 & 324 & 36.8 & 337 & 55.9 \\
\hline$+C A$ & 240 & 67.3 & 304 & 2.5 & 326 & 30.2 & 337 & 152.5 \\
\hline$+S A$ & 240 & 63.5 & 303 & 0.4 & 325 & 36.1 & 336 & 143.8 \\
\hline$+E A$ & 252 & 60.1 & 305 & 7.9 & 326 & 32.1 & 339 & 46.6 \\
\hline$+O A$ & 252 & 46.8 & 304 & 10.2 & 324 & 43.0 & 338 & 40.7 \\
\hline$+\mathrm{ME}$ & 253 & 41.7 & 304 & 19.5 & 326 & 38.8 & 339 & 27.3 \\
\hline$+\mathrm{MO}$ & 253 & 46.3 & 304 & 14.1 & 325 & 39.6 & 339 & 23.8 \\
\hline
\end{tabular}


Table S3. Portions of CD bands and compression modulus of mixed monolayers with different lipids

\begin{tabular}{|c|c|c|c|c|c|c|c|c|c|}
\hline \multirow{2}{*}{ Lipid } & \multicolumn{8}{|c|}{ proportion /\% } & \multirow{2}{*}{$\mathrm{Cs}^{-1} \max / \mathrm{mN} \mathrm{m}^{-1}$} \\
\hline & $220 \mathrm{~nm}$ & $\lambda_{t} / \mathrm{nm}$ & $240 \mathrm{~nm}$ & $\lambda_{\mathrm{t}} / \mathrm{nm}$ & $250 \mathrm{~nm}$ & $\lambda_{t} / \mathrm{nm}$ & $265 \mathrm{~nm}$ & $\lambda_{\mathrm{t}} / \mathrm{nm}$ & \\
\hline EA & 2.1 & 221 & 25.1 & 237 & 30.2 & 251 & 42.6 & 263 & 46.6 \\
\hline $\mathrm{OA}$ & 6.9 & 219 & 16.4 & 237 & 20.7 & 252 & 56.0 & 262 & 40.7 \\
\hline $\mathrm{ME}$ & 40.4 & 222 & 11.3 & 236 & 17.5 & 253 & 30.8 & 264 & 27.3 \\
\hline MO & 24.6 & 222 & 15.4 & 236 & 20.9 & 252 & 39.1 & 263 & 23.8 \\
\hline
\end{tabular}

Table S4. Portions of CD bands and compression modulus of mixed monolayers with different ratio of OA.

\begin{tabular}{cccccccccc}
\hline \multirow{2}{*}{ BBD/OA } & \multicolumn{7}{c}{ proportion $/ \%$} & \multicolumn{1}{c}{$\mathrm{Cs}^{-1}{ }_{\max } / \mathrm{mN}^{-1}$} \\
\cline { 2 - 9 } & $220 \mathrm{~nm}$ & $\lambda_{\mathrm{t}} / \mathrm{nm}$ & $240 \mathrm{~nm}$ & $\lambda_{\mathrm{t}} / \mathrm{nm}$ & $250 \mathrm{~nm}$ & $\lambda_{\mathrm{t}} / \mathrm{nm}$ & $265 \mathrm{~nm}$ & $\lambda_{\mathrm{t}} / \mathrm{nm}$ & 78.2 \\
\hline $1 / 1$ & 1.1 & 220 & 27.0 & 237 & 34.5 & 250 & 37.4 & 264 & 40.7 \\
$1 / 2$ & 6.9 & 219 & 16.4 & 237 & 20.7 & 252 & 56.0 & 262 & 37.4 \\
$1 / 5$ & 51.5 & 221 & 11.8 & 236 & 13.2 & 253 & 23.5 & 266 & 3 \\
\hline
\end{tabular}


(a)

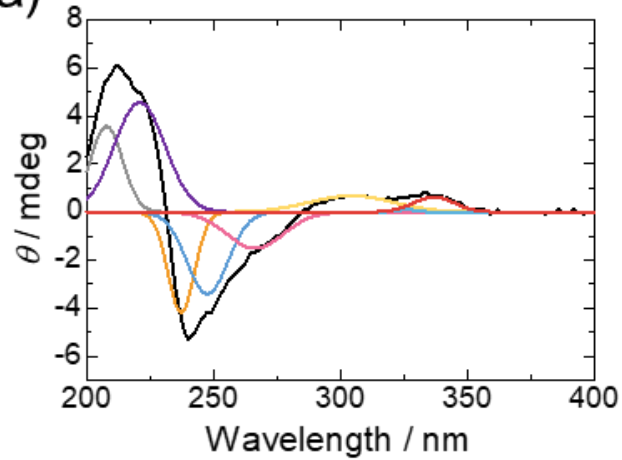

(c)

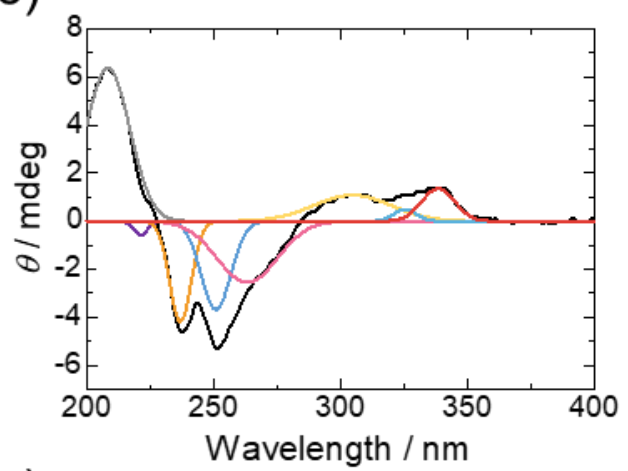

(e)

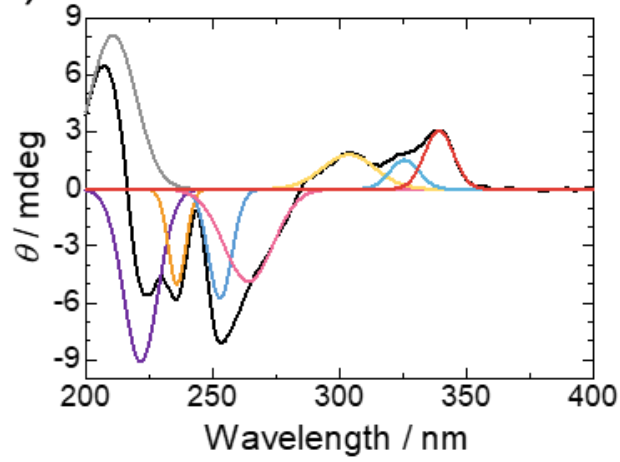

(b)

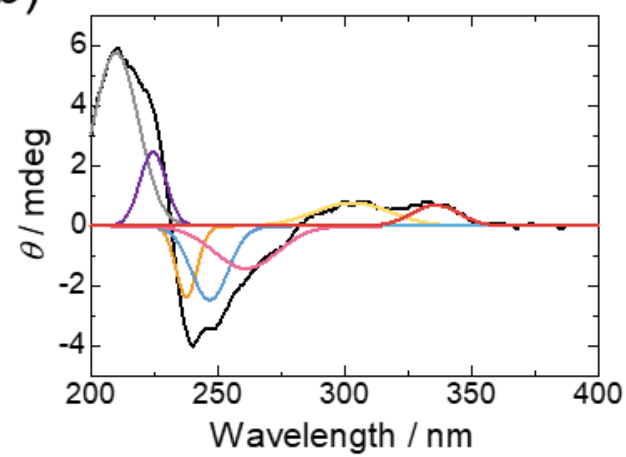

(d)

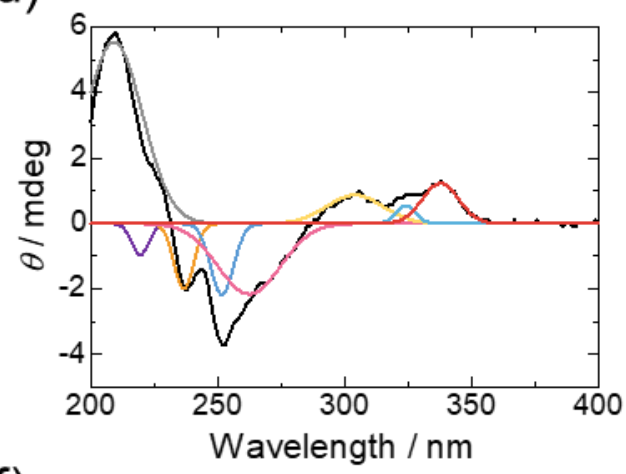

(f)

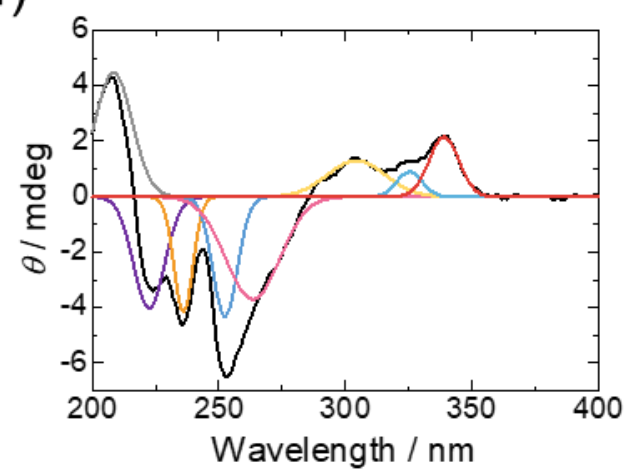

Figure S8. Separated CD spectra of mixed monolayers with (a) CA, (b) SA, (c) EA, (d) OA, (e) ME and (f) MO. 
$(a)^{-}$

(b)
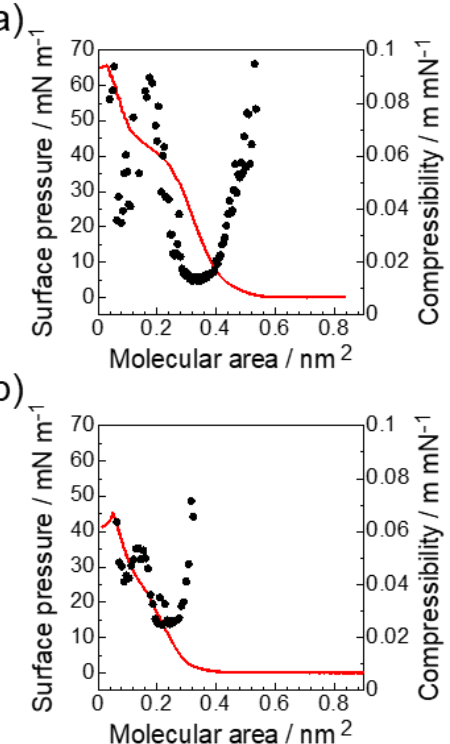

(c)

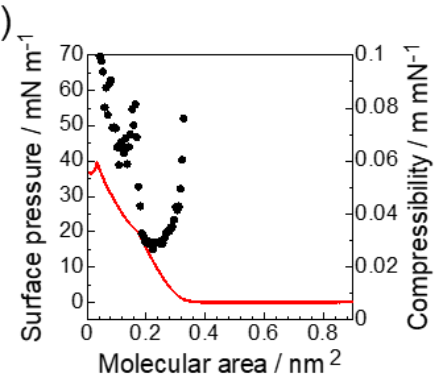

(d)

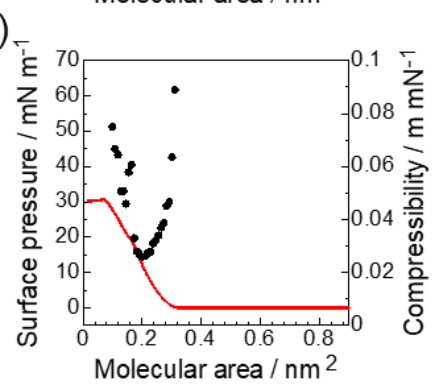

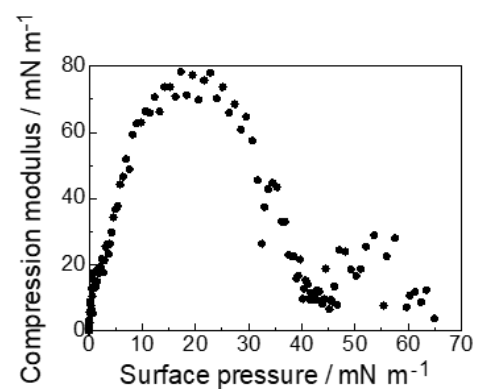
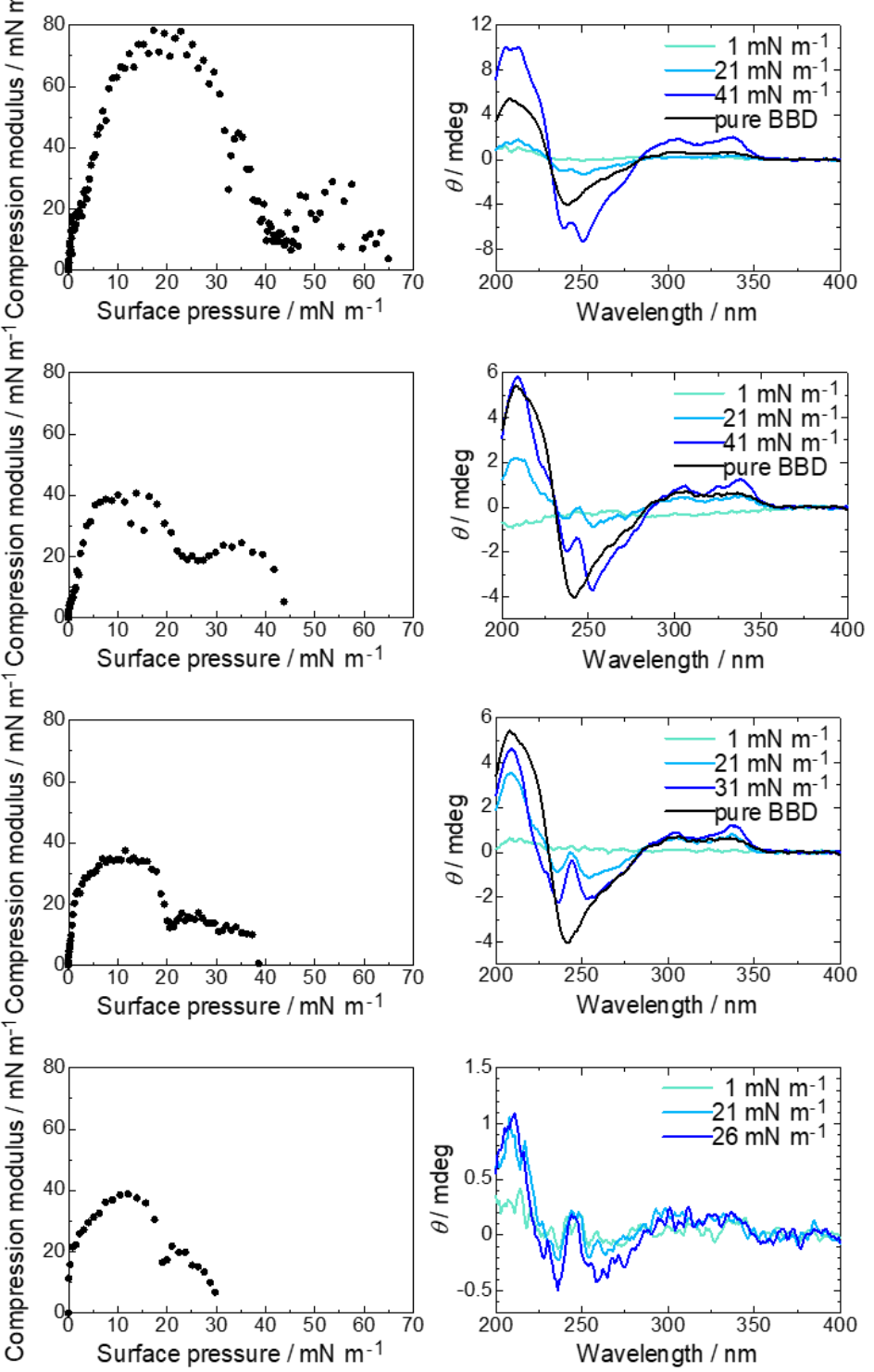

Figure S9. $C_{s}-A$ isotherms of mixed monolayers and the corresponding $\pi-A$ isotherms (shown as red line). $C s^{-1}-\pi$ curves for the mixed monolayers. $C D$ spectra of mixed monolayer with $O A$. BBD/matrix molar ratios are (a) 1/1, (b) $1 / 2$, (c) $1 / 5$, (d) $1 / 10$, respectively. 

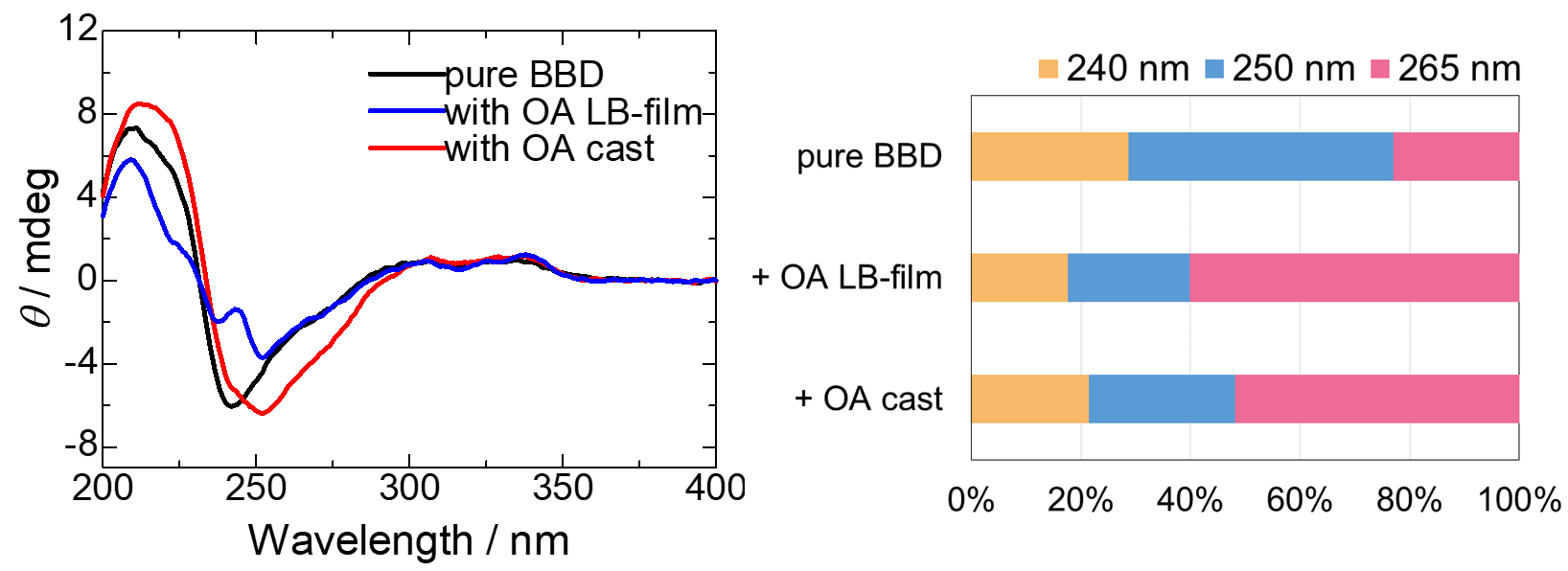

Figure S10. CD spectra and proportions of CD bands of cast films prepared from BBD and mixture with $\mathrm{BBD}$ and $\mathrm{OA}$, and mixed monolayer with $\mathrm{OA}$. 
(a) CA

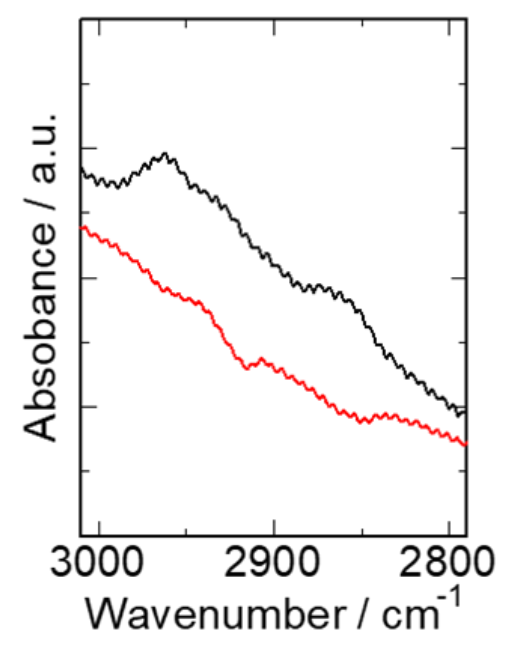

(d) OA

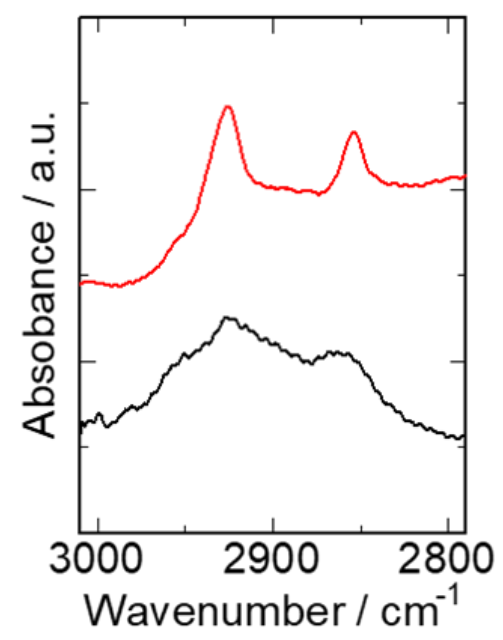

(b) SA

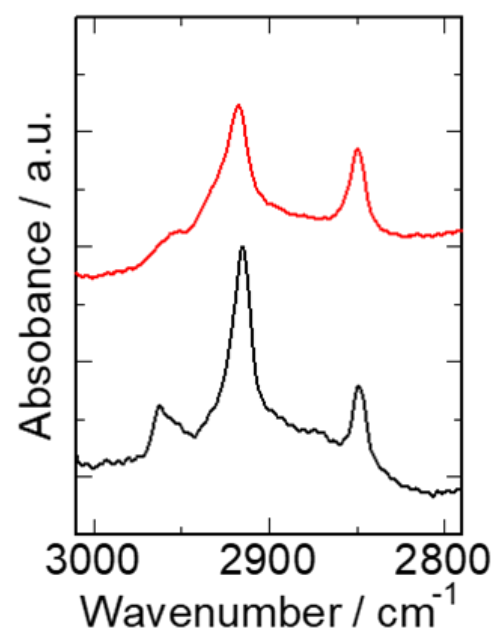

(e) ME

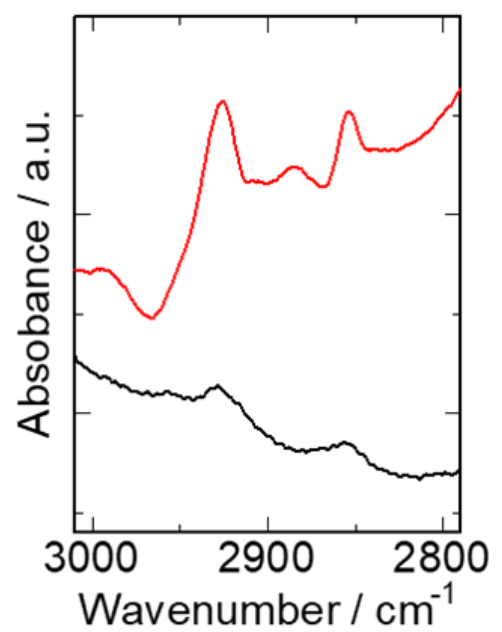

(c) $\mathrm{OA}$

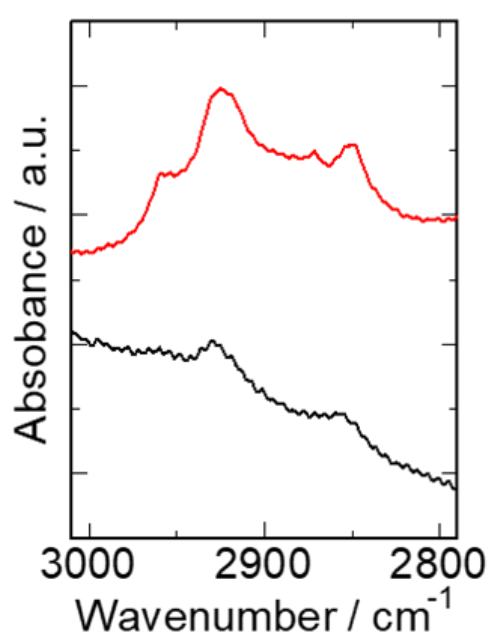

(f) $\mathrm{MO}$

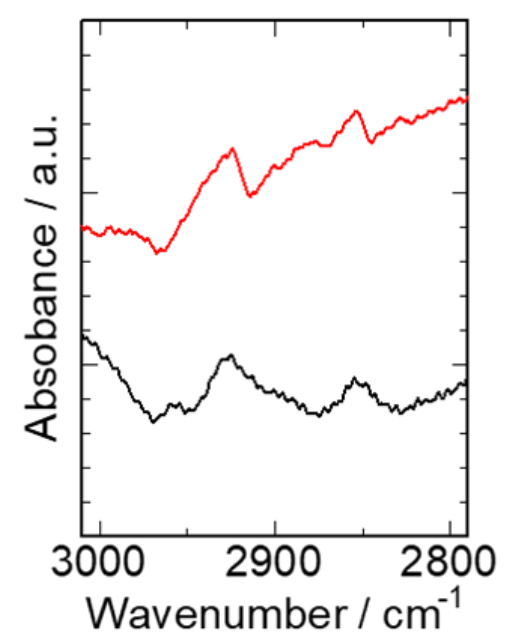

Figure S11. FTIR spectra in reflection-absorption spectral (RAS) mode of the lipid monolayer (black line) and mixed monolayer (red line) with BBD transferred on gold-deposited glass slides at different surface pressure at $20{ }^{\circ} \mathrm{C}$. (a) CA $\left(20 \mathrm{mN} \mathrm{m}^{-1}\right)$ and mixed monolayer $\left(20 \mathrm{mN} \mathrm{m}^{-1}\right)$, (b) SA (30 mN m$\left.{ }^{1}\right)$ and mixed monolayer $\left(30 \mathrm{mN} \mathrm{m}^{-1}\right)$, (c) $\mathrm{EA}\left(20 \mathrm{mN} \mathrm{m}^{-1}\right)$ and mixed monolayer $\left(40 \mathrm{mN} \mathrm{m}^{-1}\right)$, (d) OA $\left(40 \mathrm{mN} \mathrm{m}^{-1}\right)$ and mixed monolayer $\left(25 \mathrm{mN} \mathrm{m}^{-1}\right),(\mathrm{e}) \mathrm{ME}\left(20 \mathrm{mN} \mathrm{m}^{-1}\right)$ and mixed monolayer $\left(20 \mathrm{mN} \mathrm{m}^{-}\right.$ $\left.{ }^{1}\right)$, (f) $\mathrm{MO}\left(10 \mathrm{mN} \mathrm{m}^{-1}\right)$ and mixed monolayer $\left(10 \mathrm{mN} \mathrm{m}^{-1}\right)$. 
Table S5. Limiting molecular areas of BBD in admixture with OA

\begin{tabular}{llllll}
\hline & $A_{\text {mix }} / \mathrm{nm}^{2}$ & $A_{\text {id }} / \mathrm{nm}^{2}$ & $A_{\mathrm{E}} / \mathrm{nm}^{2}$ & Lim. $A_{\mathrm{BBD}} / \mathrm{nm}^{2}$ & Lim. $A_{\mathrm{OA}} / \mathrm{nm}^{2}$ \\
\hline $\mathrm{BBD} / \mathrm{OA}=1 / 1$ & 0.438 & 0.564 & -0.126 & 0.118 & 0.194 \\
$1 / 2$ & 0.301 & 0.442 & -0.141 & -0.038 & 0.179 \\
$1 / 5$ & 0.294 & 0.369 & -0.075 & -0.131 & 0.245 \\
$1 / 10$ & 0.263 & 0.345 & -0.081 & -0.571 & 0.239 \\
\hline
\end{tabular}

$A_{\text {mix }}$ : molecular area of mixed monolayers, $A_{\text {id }}$ : ideal cross-sectional area of mixed monolayers, $A_{\mathrm{OA}}+$ $A_{\mathrm{BBD}} / 2, A_{\mathrm{OA}}$ : molecular area of $\mathrm{OA}, 0.32 \mathrm{~nm}^{2}, A_{\mathrm{BBD}}$ : molecular area of $\mathrm{BBD}, 0.24 \mathrm{~nm}^{2}, A_{\mathrm{E}}$ : difference between $A_{\text {mix }}$ and $A_{\text {id }}$, Lim. $A_{\mathrm{BBD}}$; Limiting molecular area of BBD in lipid, 2( $\left.A_{\text {mix }}-A_{\text {lip }}\right)$, Lim. $A_{\mathrm{OA}}$ : Limiting molecular area of $\mathrm{OA}$ in $\mathrm{BBD}, A_{\mathrm{mix}}-A_{\mathrm{BBD}} / 2$. 
(a) Anti-1 part 1s

(b) Anti-2 part 1s

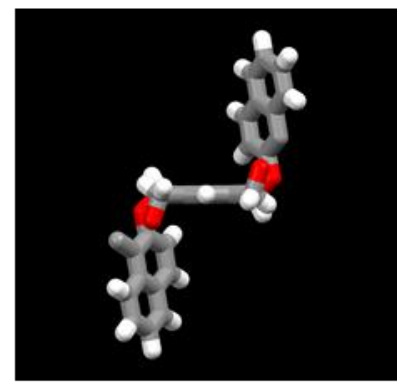

(c) Syn-1 part 1s

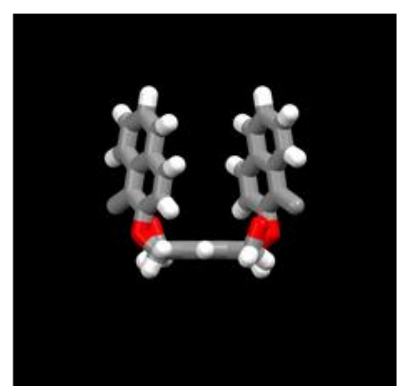

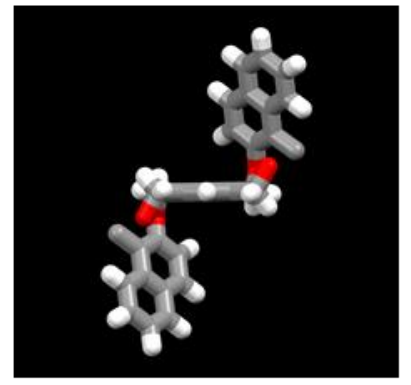

(d) Syn-2 part 1s

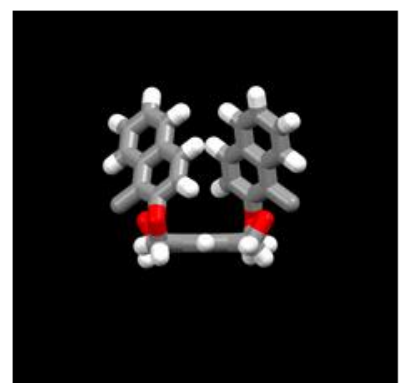

Figure S12. Optimized conformations of BBD, (a) anti-1 part 1s, (b) anti-2 part 1s, (c) syn-1 part 1s, (d) syn-2 part 1s.

(a) Anti-1 part 2s

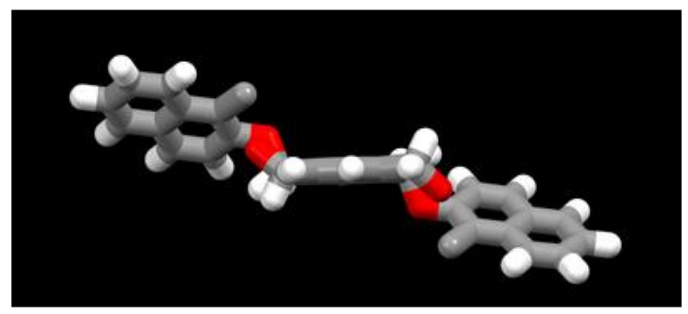

(c) Syn-1 part 2s

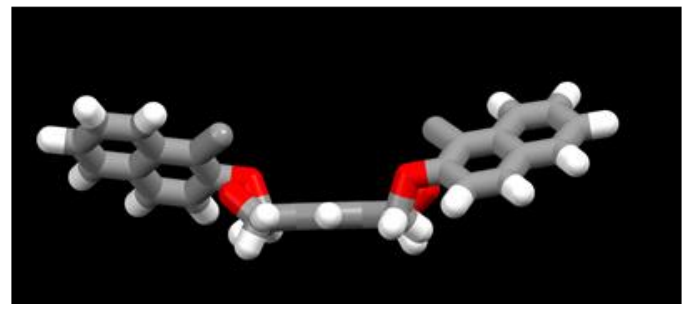

(b) Anti-2 part 2s

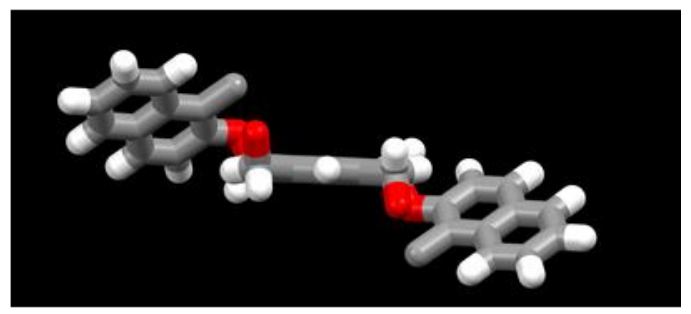

(d) Syn-2 part $2 \mathrm{~s}$

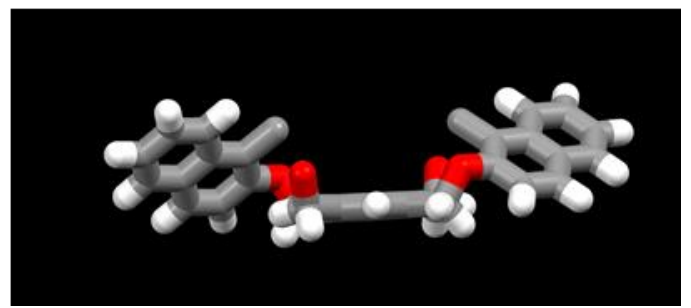

Figure S13. Optimized conformations of BBD, (a) anti-1 part 2s, (b) anti-2 part 2s, (c) syn-1 part 2s, (d) syn-2 part 2s. 
Computational Methods and Results for Simulation of CD Signals

All calculations were performed using the Gaussian 16 program, ${ }^{1}$ and the results were analyzed and visualized on GaussView 6.0.16. Calculations were performed at the density functional theory (DFT) level with the B3LYP functional, the gradient correction of the exchange functional by Becke ${ }^{2,3}$ and the correlation functional by Lee, Yang and Parr, ${ }^{4}$ and the $6-31 G(d, p)$ split valence plus polarization basis set $^{5-9}$ was used. Chiral $(R, R)$-BBD was used for calculations and is abbreviated without the chiral denotation for simplification. Five conformers were found for BBD. Those where the two binaphthyls are position on the same side relative to the central phenyl group are expressed as syn, those with binaphthyls on opposing sides are antil. Those with both binaphthyls approximately coplanar with the central moiety is expressed as flat. Since two conformers were found for both anti and syn, they were distinguished by adding the numbers -1 and -2 , where -1 is more stable than -2 . Thus, five conformers, anti-1-, anti-2-, syn-1-, syn-2-, and flat-BBD were found as optimized structures. ${ }^{10} C_{2}$ symmetry was used for anti-1-, anti-2-, syn-1-, syn-2-BBD, and $D_{2}$ for flat-BBD, respectively. To analyze the effect of torsion angle of durene and naphthalene on CD spectra, partial structures consisting of durene and one naphthalene were extracted from each BBD conformer except for flat-BBD. Subsequent simulation of the CD signals were performed without further structural optimization. Hydrogen atoms were added at cleaved bonds. Since syn and anti conformers have $C_{2}$ symmetry, two of the four naphthalenes were selected for analysis and the partial structures are denoted part1 or part2. 


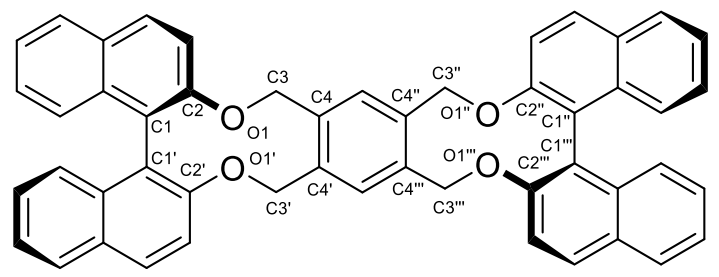

Scheme S1 Chemical structure of BBD

Table S6. Dihedral angle and relative energies of each conformers of BBD

\begin{tabular}{cccccc}
\hline Dihedral angle & anti-1 & anti-2 & syn-1 & syn-2 & flat-BBD \\
\hline Energy (kcal/mol) & 0.0 & 5.4 & 0.4 & 5.3 & 19.5 \\
\hline C2-C1-C1'-C2' $(\theta)$ & -63.8 & -89.1 & -63.9 & -88.8 & -60.5 \\
C2"-C1"-C1'"-C2"' $(\theta)$ & -63.8 & -89.1 & -63.9 & -88.8 & -60.5 \\
C2-O1-C3-C4 & -61.7 & 53.2 & -61.6 & 52.1 & -158.9 \\
C2'-O1'-C3'-C4' & -144.6 & -114.5 & -144.1 & -113.7 & -158.9 \\
C2"-O1"-C3"-C4" & -61.7 & -114.5 & -144.1 & -113.7 & -158.9 \\
C2"'-O1'"-C3'"-C4"' & -144.6 & 53.2 & -61.6 & 52.1 & -158.9 \\
\hline
\end{tabular}

Table. S7 Intervening distances between durene and naphthalene

\begin{tabular}{|c|c|}
\hline & Distance $(\AA)$ \\
\hline Anit-1 part2 & 7.156 \\
\hline Syn-1 part2 & 7.157 \\
\hline Anit-2 part2 & 6.695 \\
\hline Syn-2 part2 & 6.687 \\
\hline
\end{tabular}


The scan calculations for the partial structure of BBD (= half-BBD) were performed at the B3LYP/6$31 \mathrm{G}(\mathrm{d}, \mathrm{p})$ level as a function of dihedral angle (C2-O1-C3-C4) without restriction of other dihedral angle (C2'-O1'-C3'-C4') and other parts. The relaxed potential energy surface (PES) scan was performed by varying the dihedral angle in $20^{\circ}$ steps in either clockwise or anticlockwise directions. Judging from the dihedral angles (C2-O1-C3-C4 and C2'-O1'-C3'-C4'), two conformers were assigned to be the partial structure of anti-1/syn-1-BBD (= half-1-BBD) and that of anti-2/syn-2-BBD (= half-2BBD). The scan analysis was started from the most stable conformer, half-1-BBD.

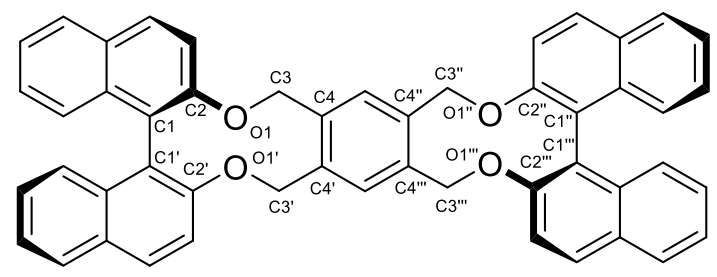

anti-1/syn-1/anti-2/syn-2-BBD<smiles></smiles>

half-1/2-BBD

Scheme S2 Chemical structures of BBD and half-BBD

Table S8. Dihedral angles and relative energies of the partial structure of anti-1/syn-1-BBD and anti2/syn-2-BBD, which correspond to half-1-BBD and half-2-BBD, respectively.

$$
\text { half-1-BBD half-2-BBD }
$$

Dihedral angle (Partial structure of (Partial structure of

\begin{tabular}{ccc} 
& anti-1/syn-1-BBD) & anti-2/syn-2-BBD) \\
\hline Energy (kcal/mol) & 0 & 2.8 \\
\hline C2-C1-C1'-C2'( $\theta)$ & -63.5 & -88.9 \\
C2-O1-C3-C4 & -61.5 & 53.2 \\
C2'-O1'-C3'-C4' & -144.9 & -114.6 \\
\hline
\end{tabular}




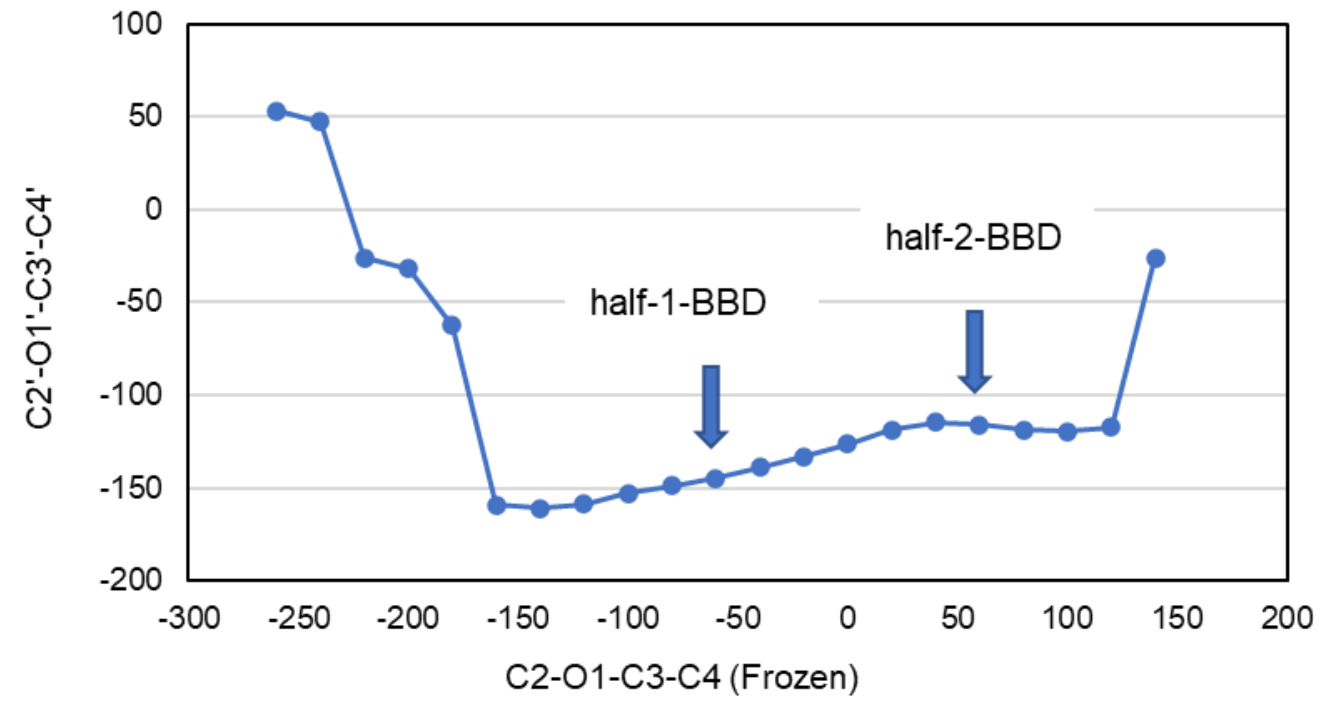

Figure. S14. Variation in dihedral angle during scan analysis when the dihedral angle C2-O1-C3-C4 is varied and fixed. Positions of the conformers, half-1-BBD and half-2-BBD, are indicated with arrows.

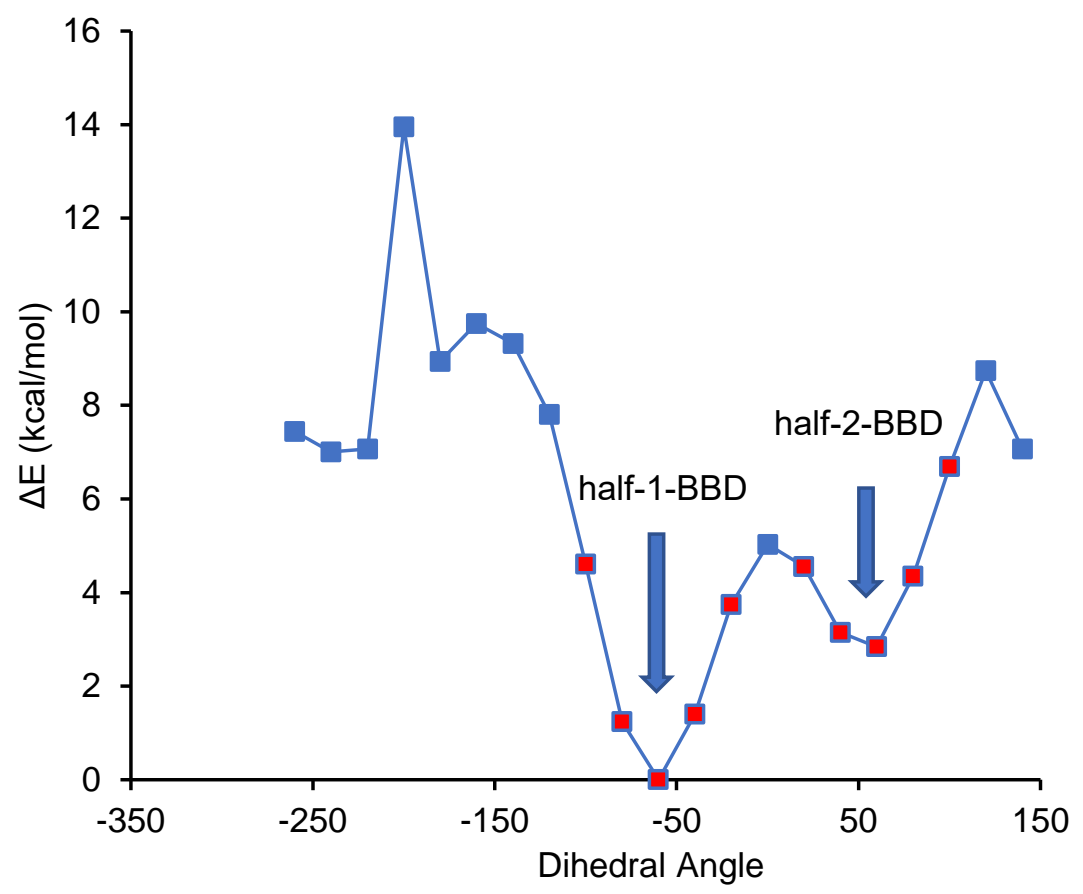

Figure. S15. Relative energies of half-BBD when the dihedral angle C2-O1-C3-C4 was varied and fixed, and the other parts are relaxed. Points of the conformers, half-1-BBD and half-2-BBD, are indicated with arrows. The red points indicate where CD simulations were performed. 
The results of scan analysis show that the conformation of half-BBD, and thus also BBD are restricted due to the cyclic structures. Only two stable conformers were found, which are assigned to be the partial structure of BBD conformers, syn-1/anti-1 and syn-2/anti-2, from the dihedral angles (C2-O1C3-C4 and C2'-O1'-C3'-C4').

Simulation of CD spectra was performed for each of the conformers of BBD and its partial structures by time-dependent DFT (TD DFT) for the first 200 singlet-singlet transitions for BBD and 100 for the partial structures. Note that, although the spectral analysis with the B3LYP functional yields excellent consistency in the ordering of states with the experimental results, it tends to underestimate the excitation energy to afford slightly red-shifted theoretical spectra. ${ }^{11}$ The spectra with convoluted curves were obtained with peak half-width of $0.333 \mathrm{eV}$ at the half height.

To obtain the CD spectra of the major conformers, simulation of CD spectra was performed for the structure of local minima and those with dihedral angle C2-O1-C3-C4 deviated by $\pm 20^{\circ}$ and $\pm 40^{\circ}$ from the local minima as shown in Fig. S16. In this range, the simulated CD spectra were similar to those of corresponding local minima. Thus, we have confirmed that the conformation can be assigned from CD spectra.

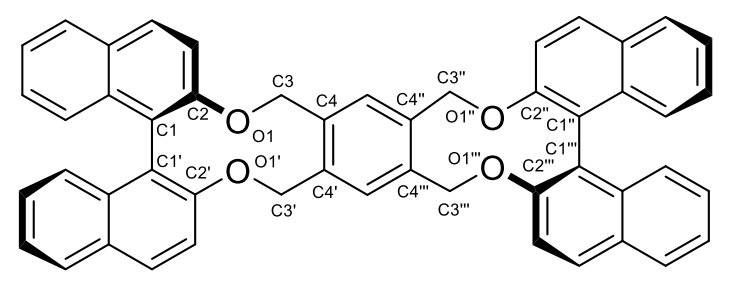

BBD

conformers: anti-1/syn-1/anti-2/syn-2-BBD anti-1/syn-1/anti-2/syn-2-

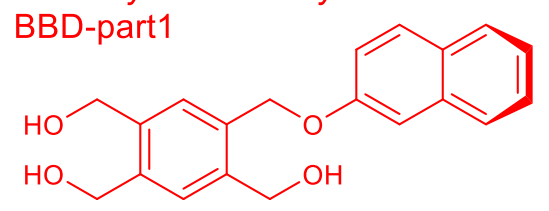

anti-1/syn-1/anti-2/syn-2-

BBD-part2<smiles>OCc1cc(CO)c(COc2ccc3ccccc3c2)cc1CO</smiles>

half-BBD-part1<smiles>OCc1ccccc1COc1ccc2ccccc2c1</smiles>

half-BBD-part2<smiles>OCc1ccccc1COc1ccc2ccccc2c1</smiles>

half-BBD (for scan analysis) conformers: half-1/2-BBD

Scheme S3 Chemical structures of BBD and half-BBD part 1 and part 2 including the central durene and naphthyl moieties, respectively. 
(a) anti1-Part1

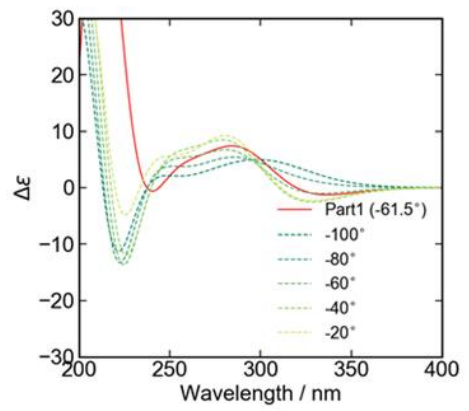

(c) anti2-Part1

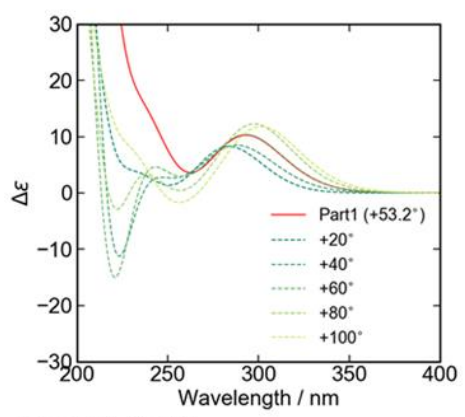

(e) syn1-Part1

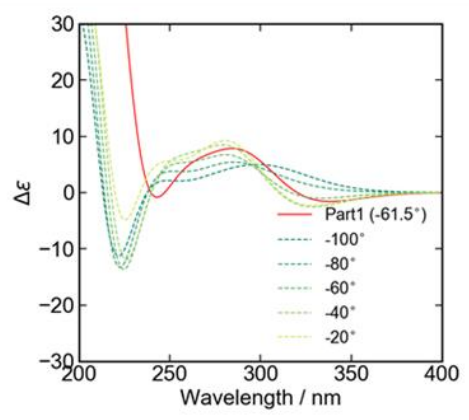

(g) syn2-Part1

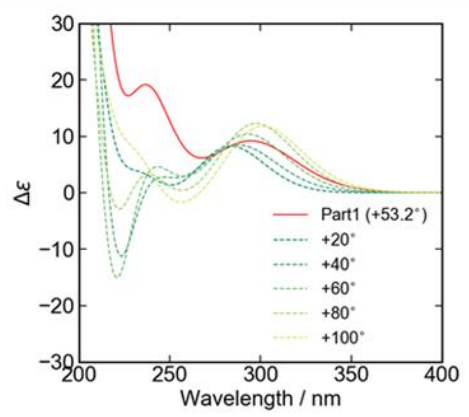

(b) anti1-Part2

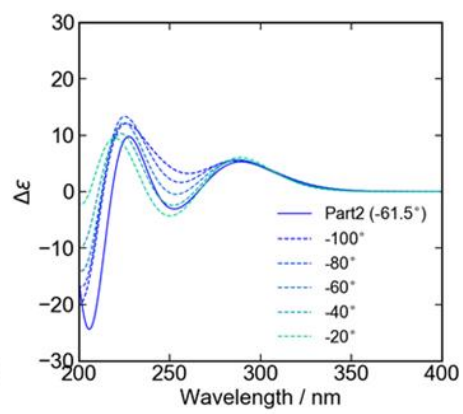

(d) anti2-Part2

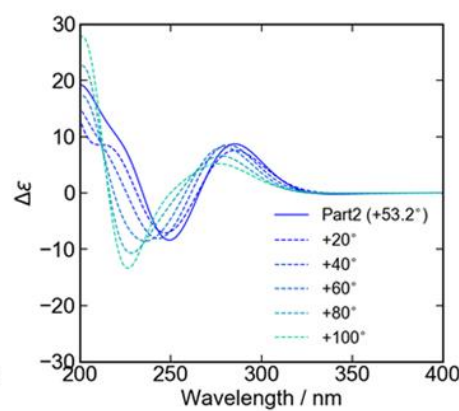

(f) syn1-Part2

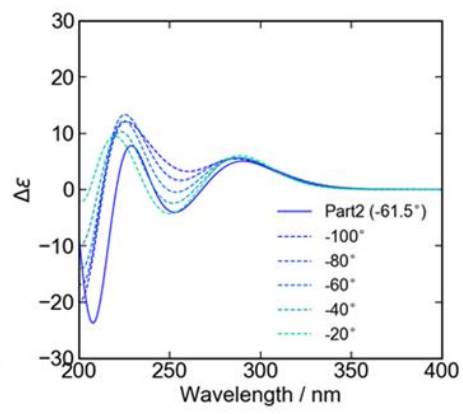

(h) syn2-Part2

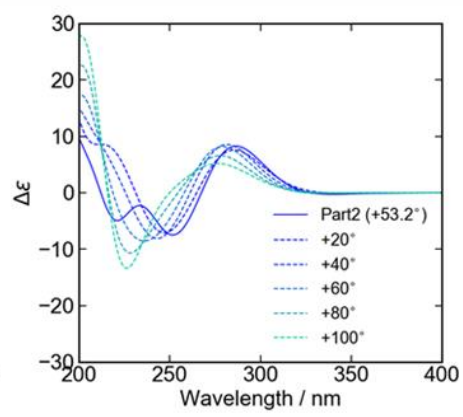

Figure S16. Simulated CD spectra of the partial structure of half-BBD (half-BBD-part1 (a,b,e,f) or halfBBD-part2 $(\mathrm{c}, \mathrm{d}, \mathrm{g}, \mathrm{h}))$ in dash lines. The partial structures (half-BBD-part1/2) were obtained from the scan analysis of half-BBD with dihedral angle C2-O1-C3-C4 as indicated and one of the naphthalene groups was omitted and replaced with a proton. The partial structures of BBD, anti1/syn1/anti2/syn2BBD-part1 (= anti1/syn1/anti2/syn2-Part1) or anti1/syn1/anti2/syn2-BBD-part2 $\quad(=$ anti1/syn1/anti2/syn2-Part2), are also shown as red or blue lines, respectively. 

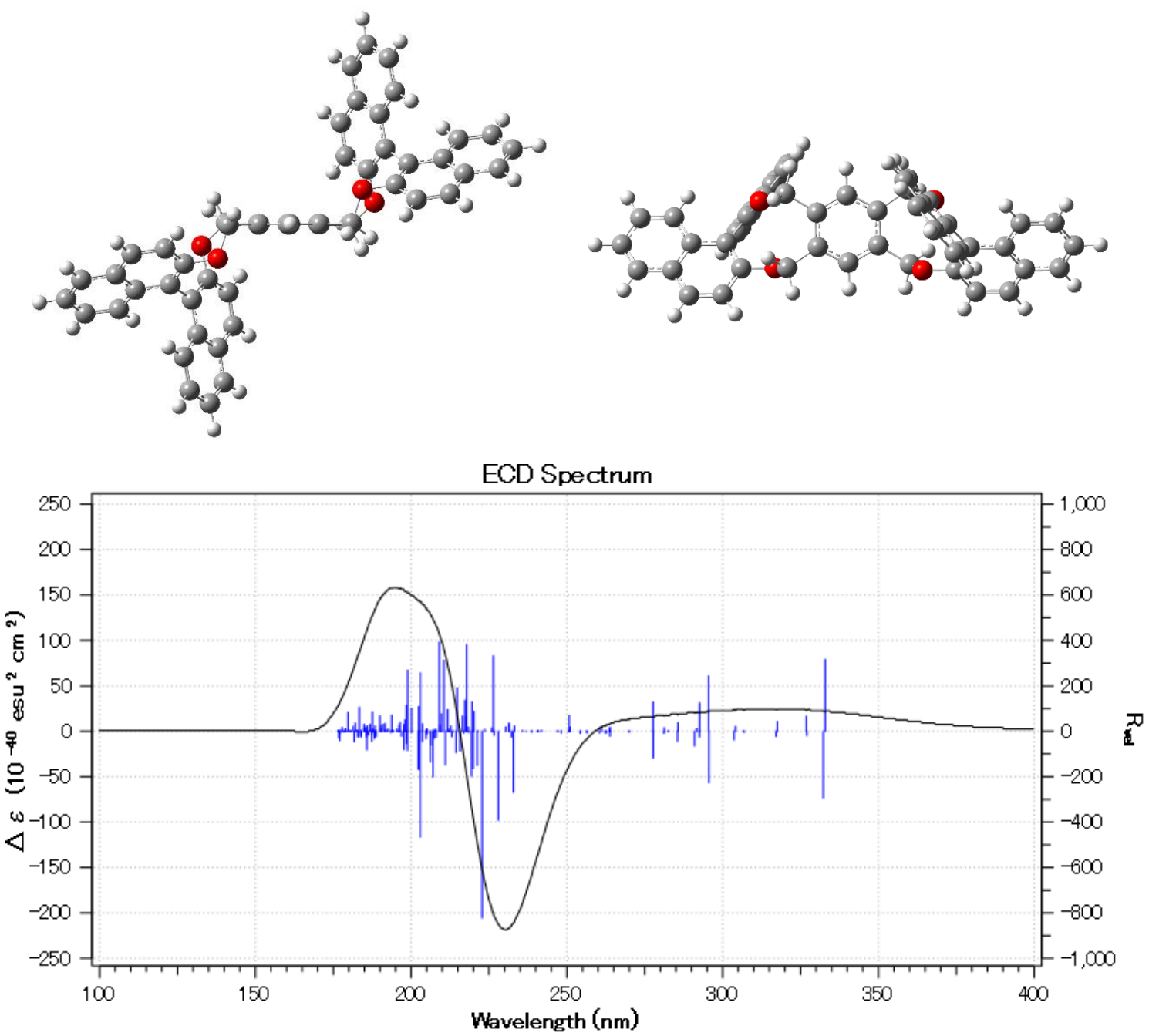

Figure S17. Structure and simulated CD spectrum of anti-1 conformation. 

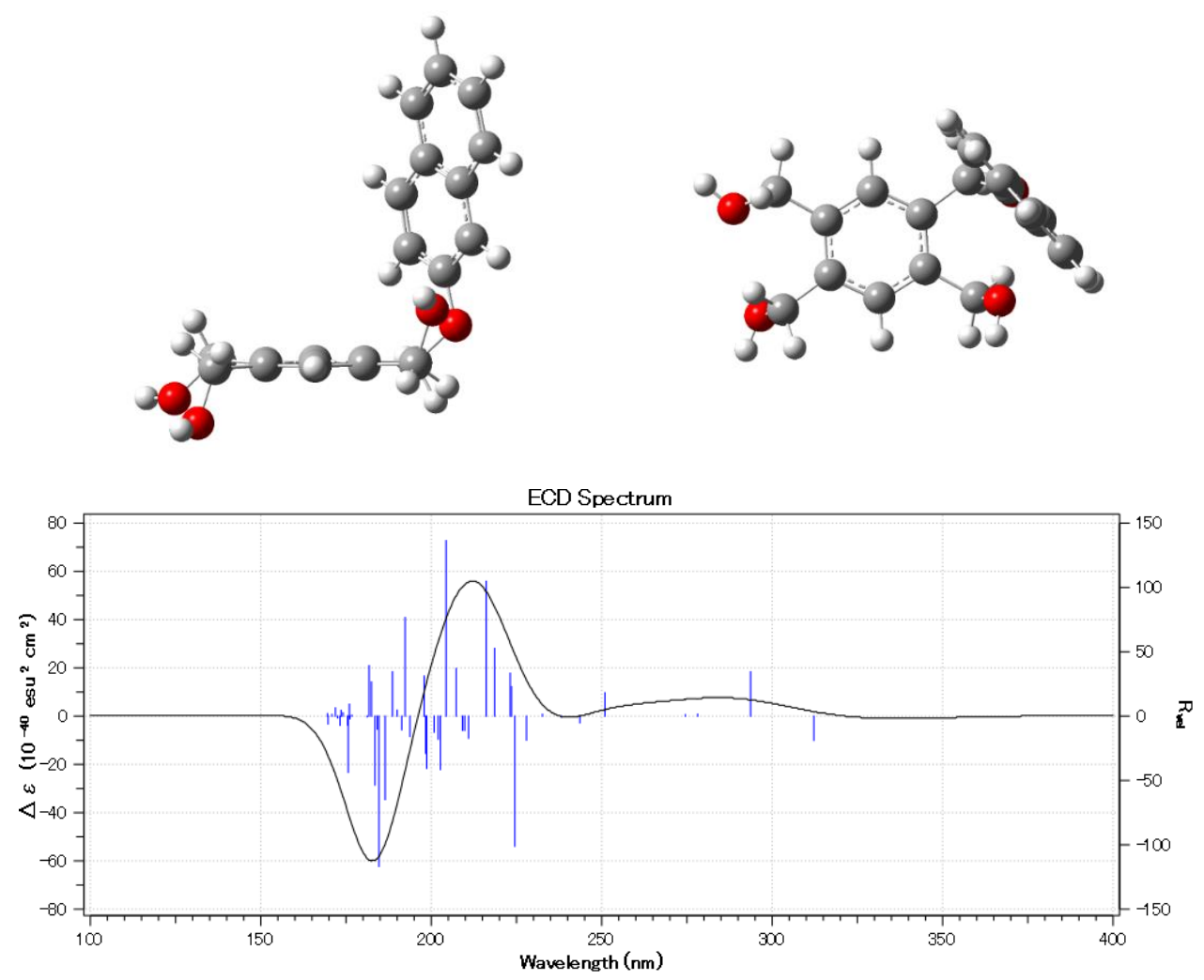

Figure S18. Structure and simulated CD spectrum of part 1 in anti-1 conformation.
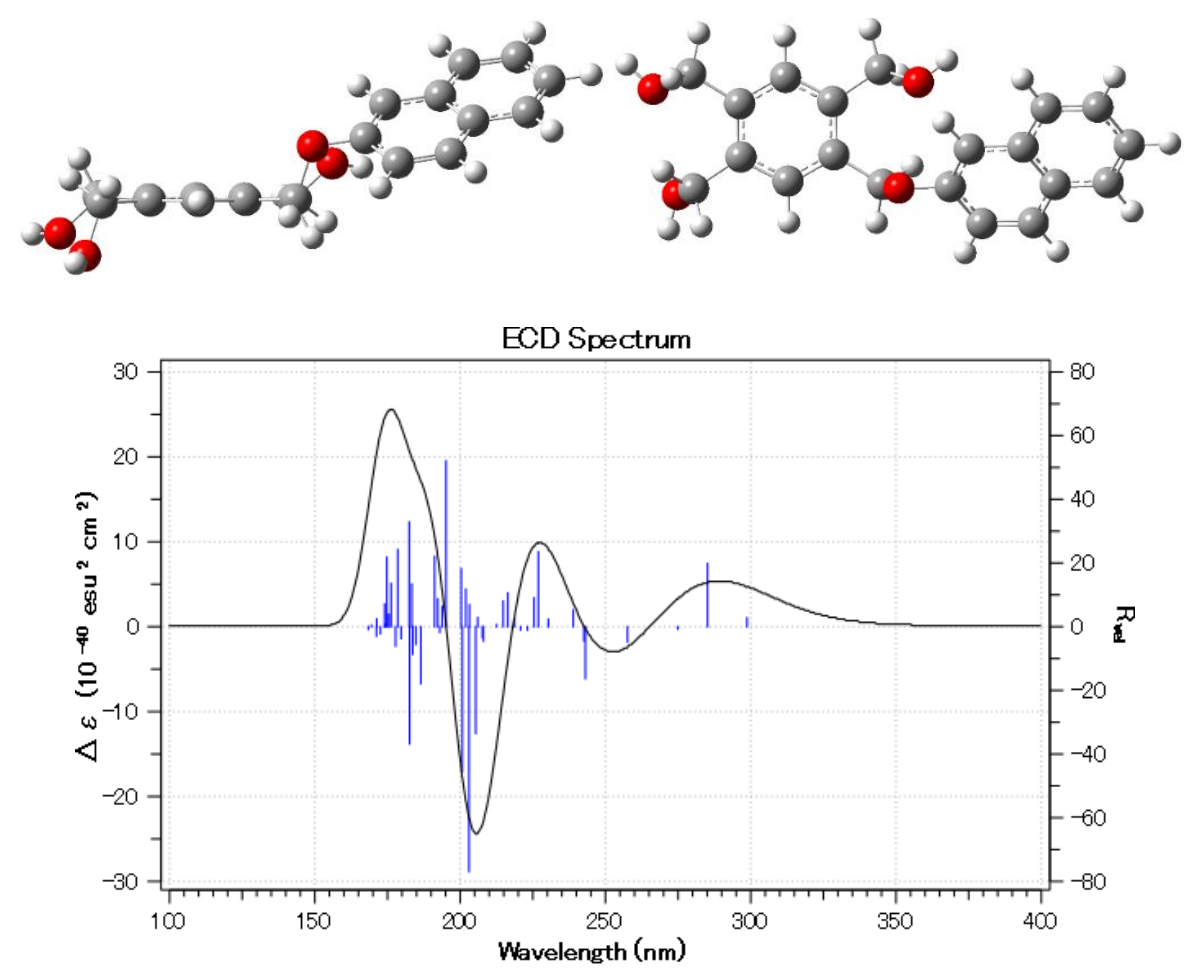

Figure S19. Structure and simulated CD spectrum of part 2 in anti-1 conformation. 

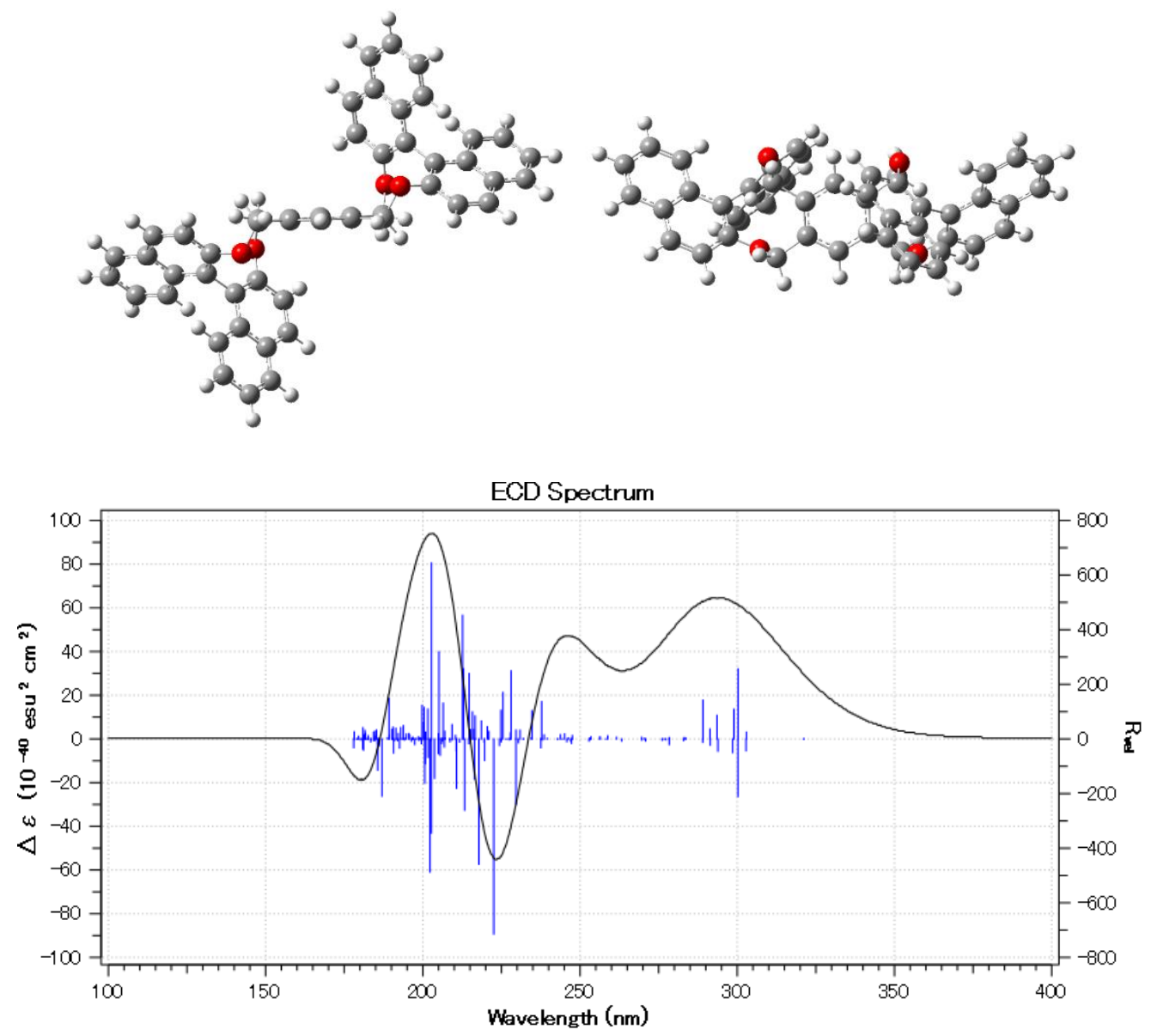

Figure S20. Structure and simulated CD spectrum of anti-2 conformation. 

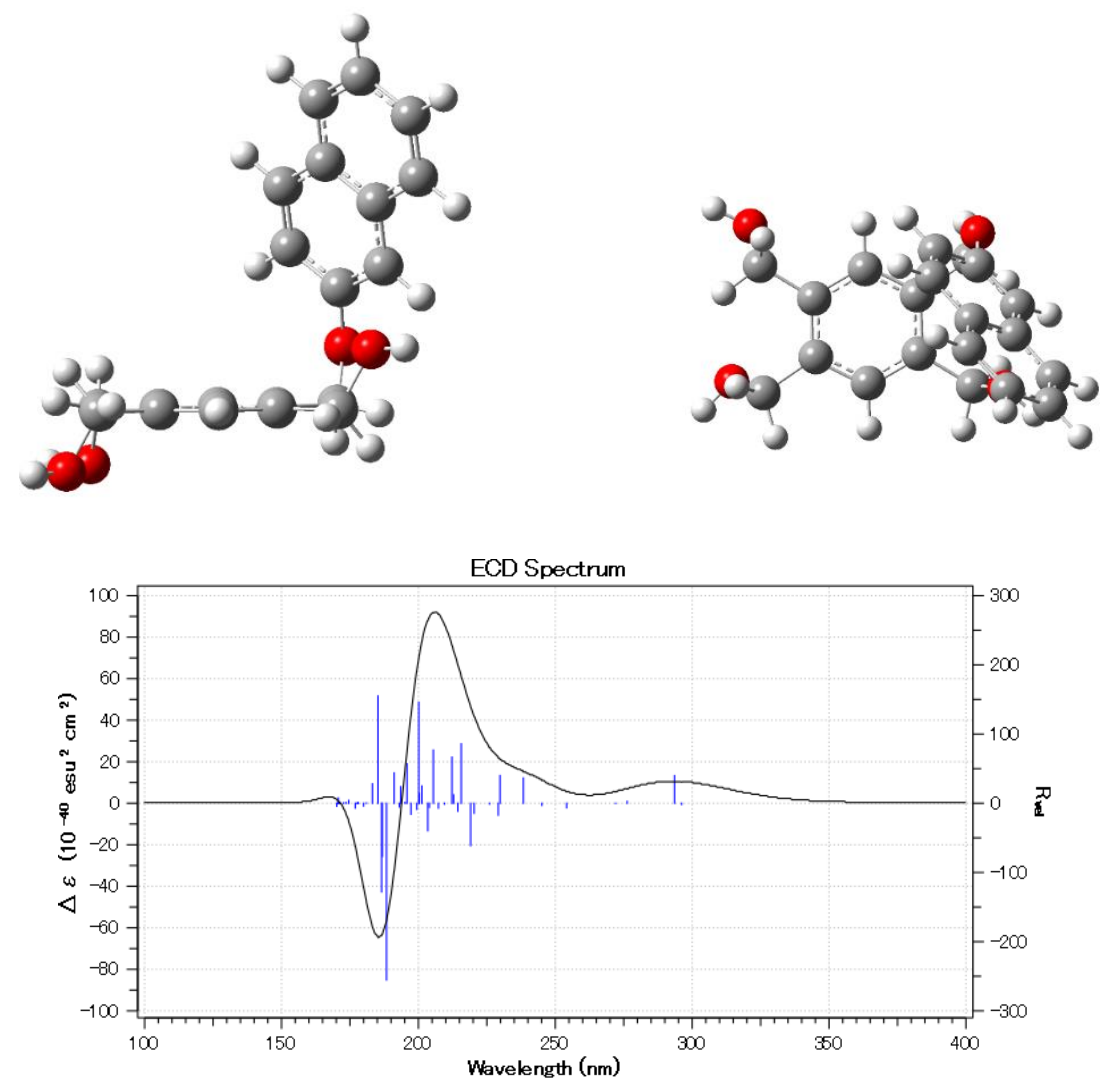

Figure S21. Structure and simulated CD spectrum of part 1 in anti-2 conformation.
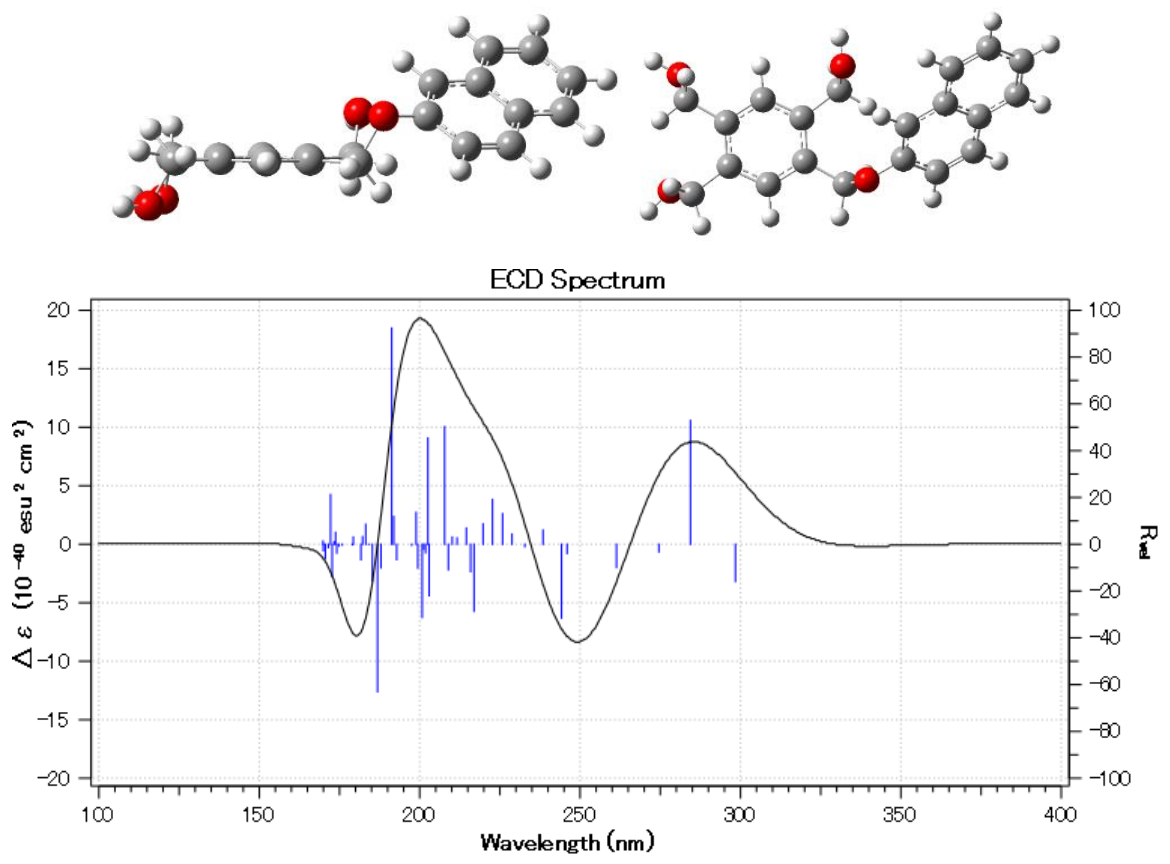

Figure S22. Structure and simulated CD spectrum of part 2 in anti-2 conformation. 

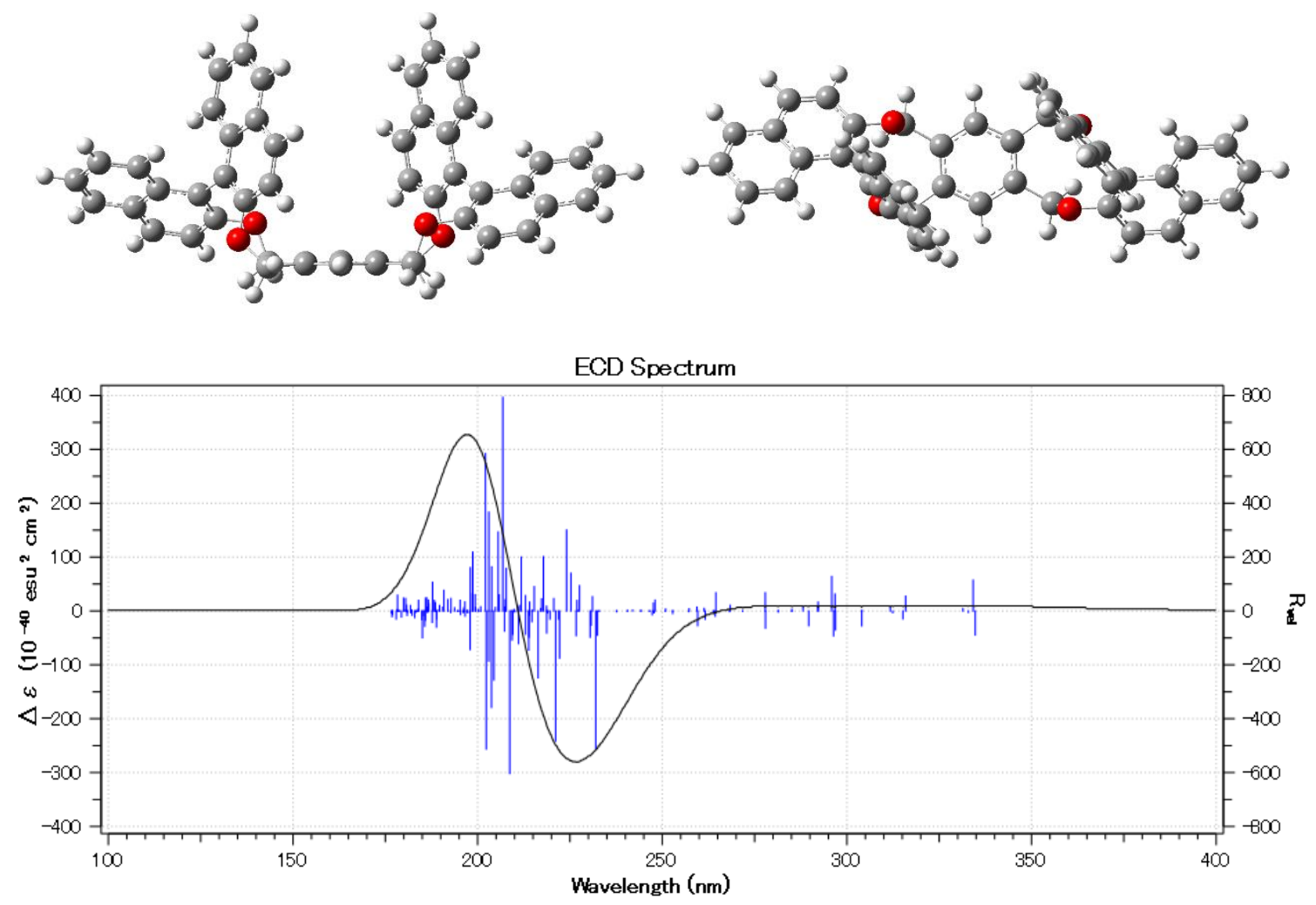

Figure S23. Structure and simulated CD spectrum of syn-1 conformation. 

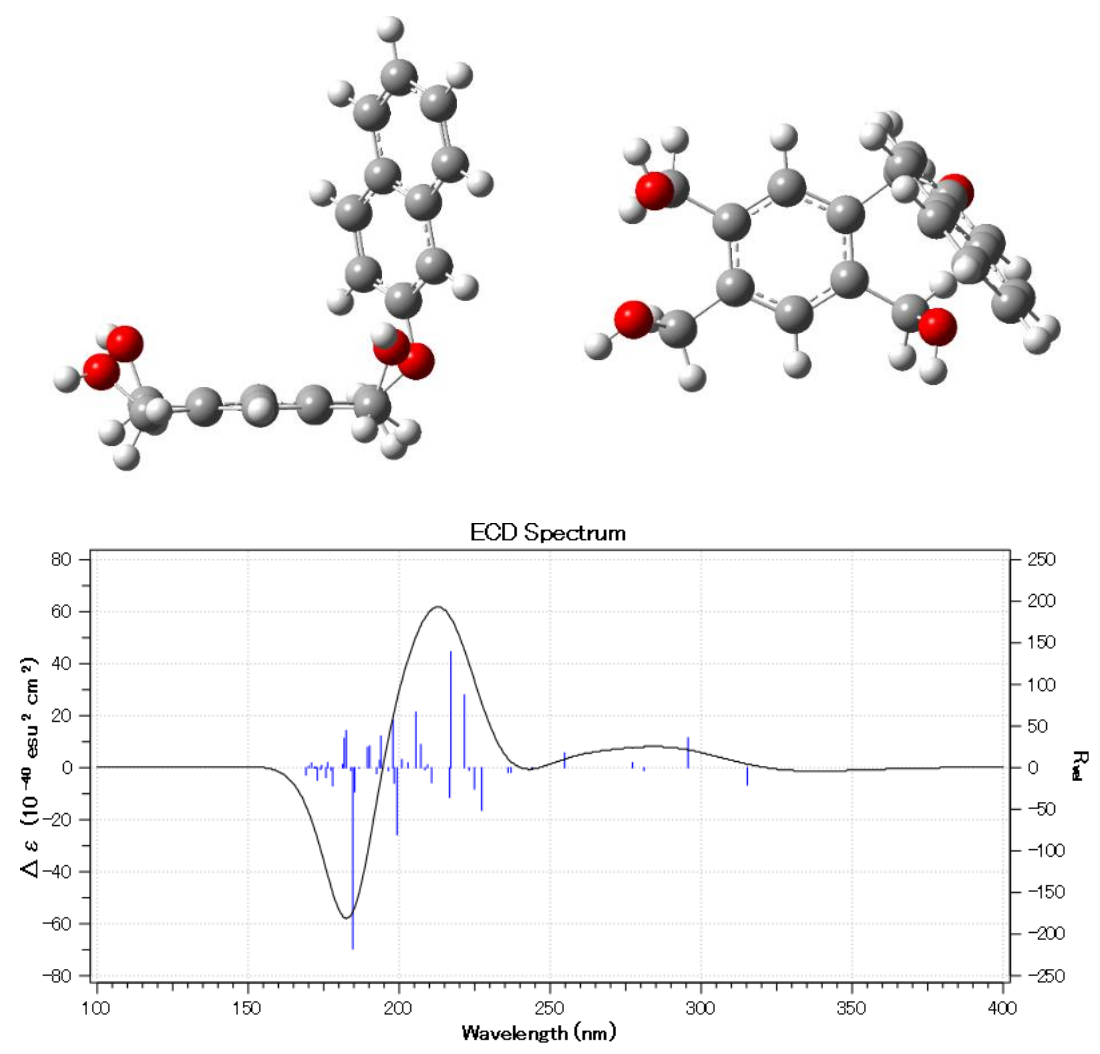

Figure S24. Structure and simulated CD spectrum of part 1 in syn-1 conformation.
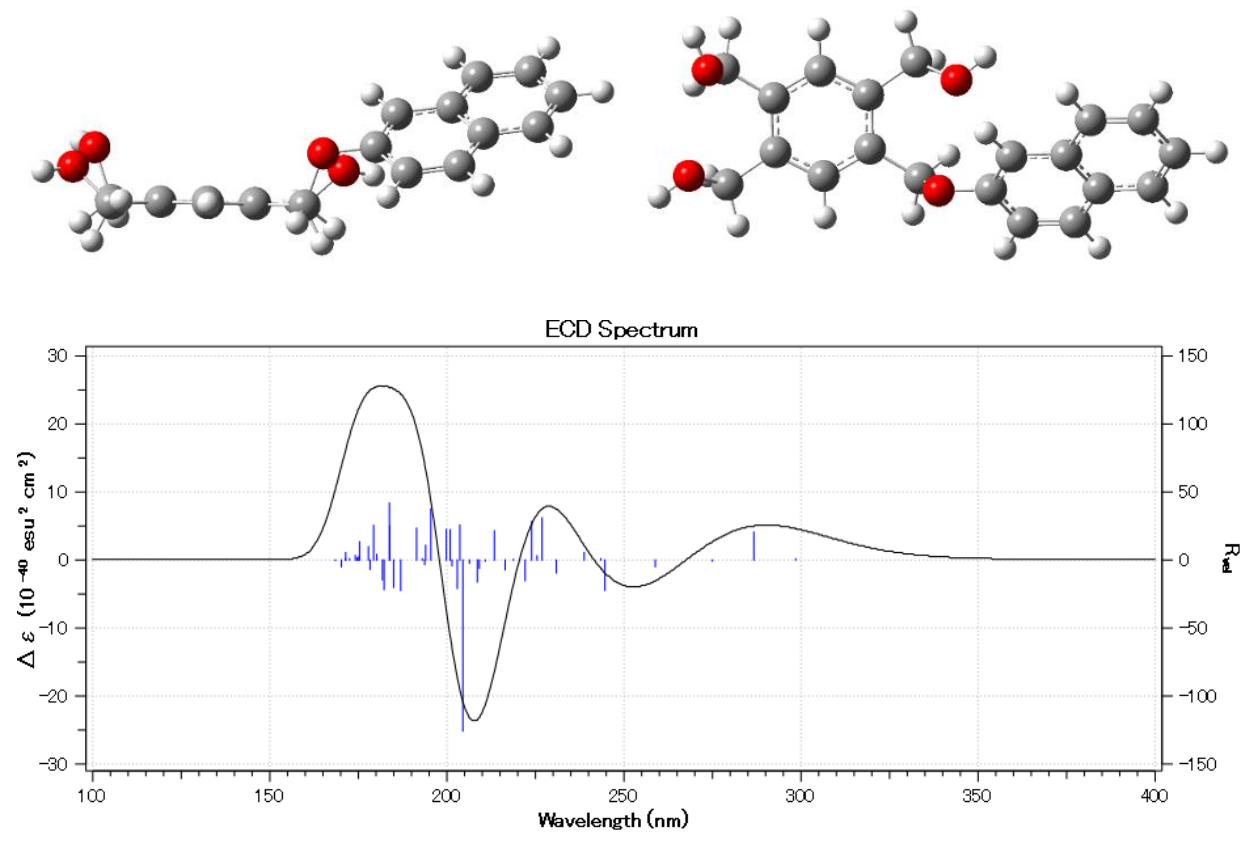

Figure S25. Structure and simulated CD spectrum of part 2 in syn-1 conformation. 

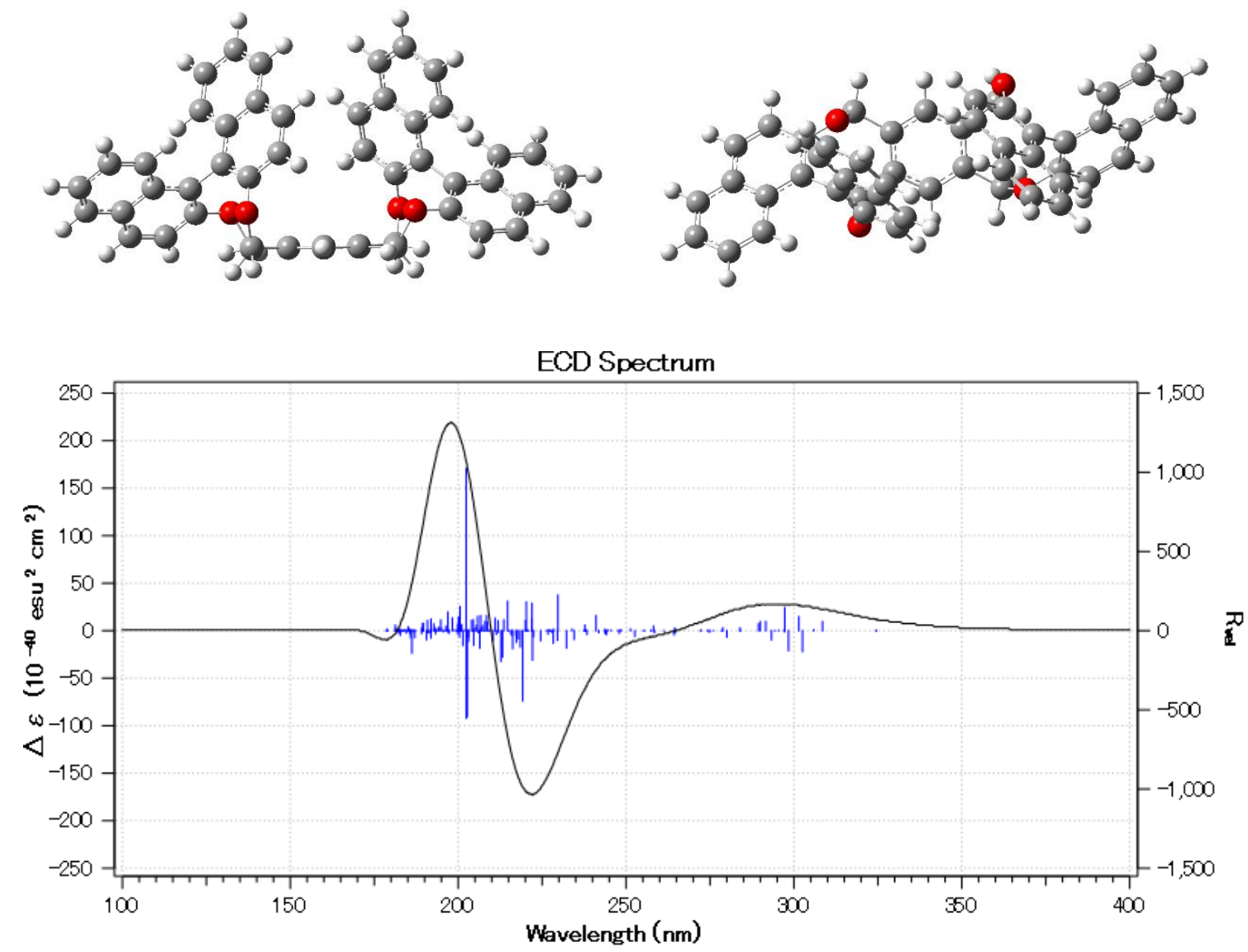

Figure S26. Structure and simulated CD spectrum of syn-2 conformation. 

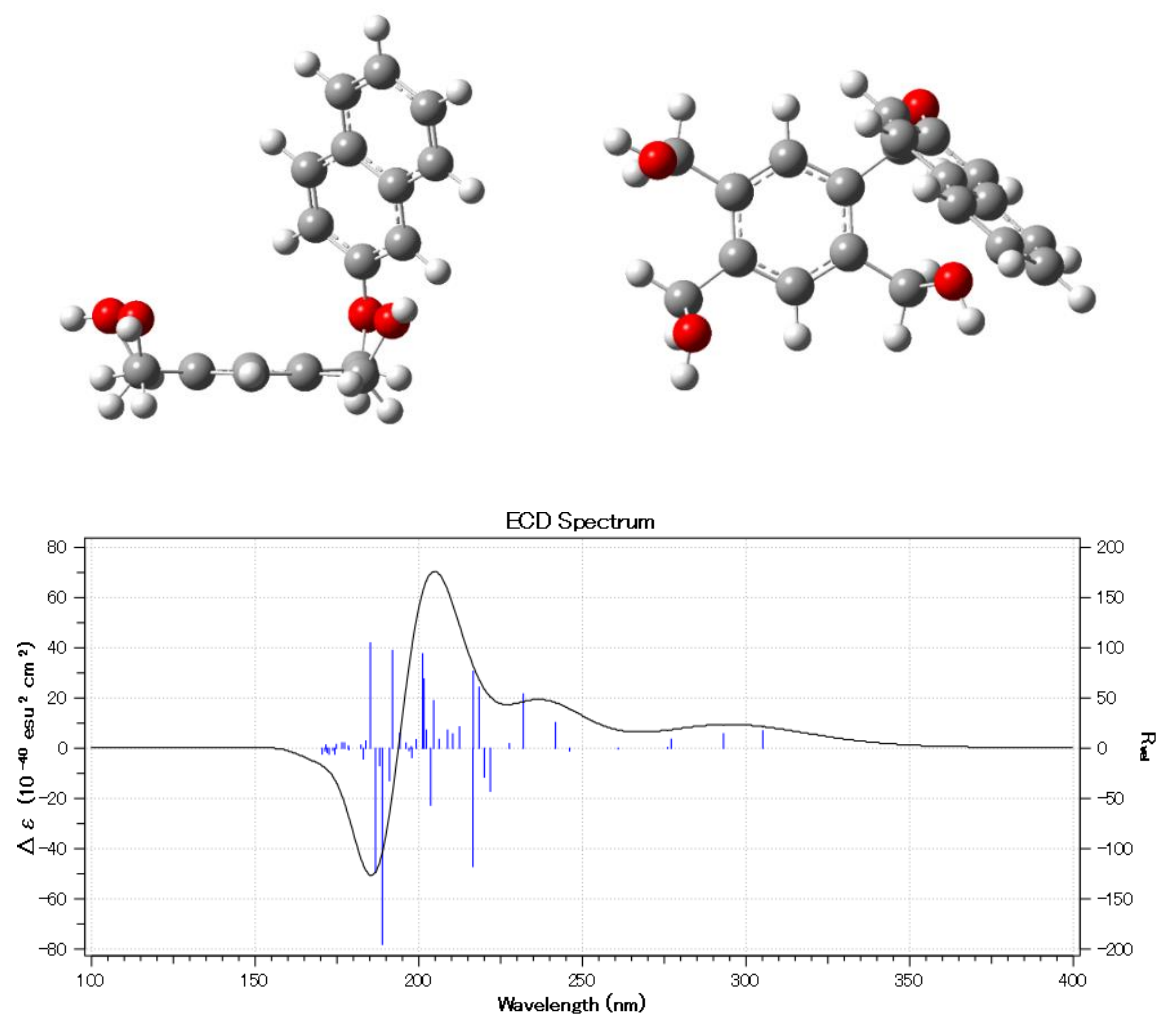

Figure S27. Structure and simulated CD spectrum of part 1 in syn-2 conformation.
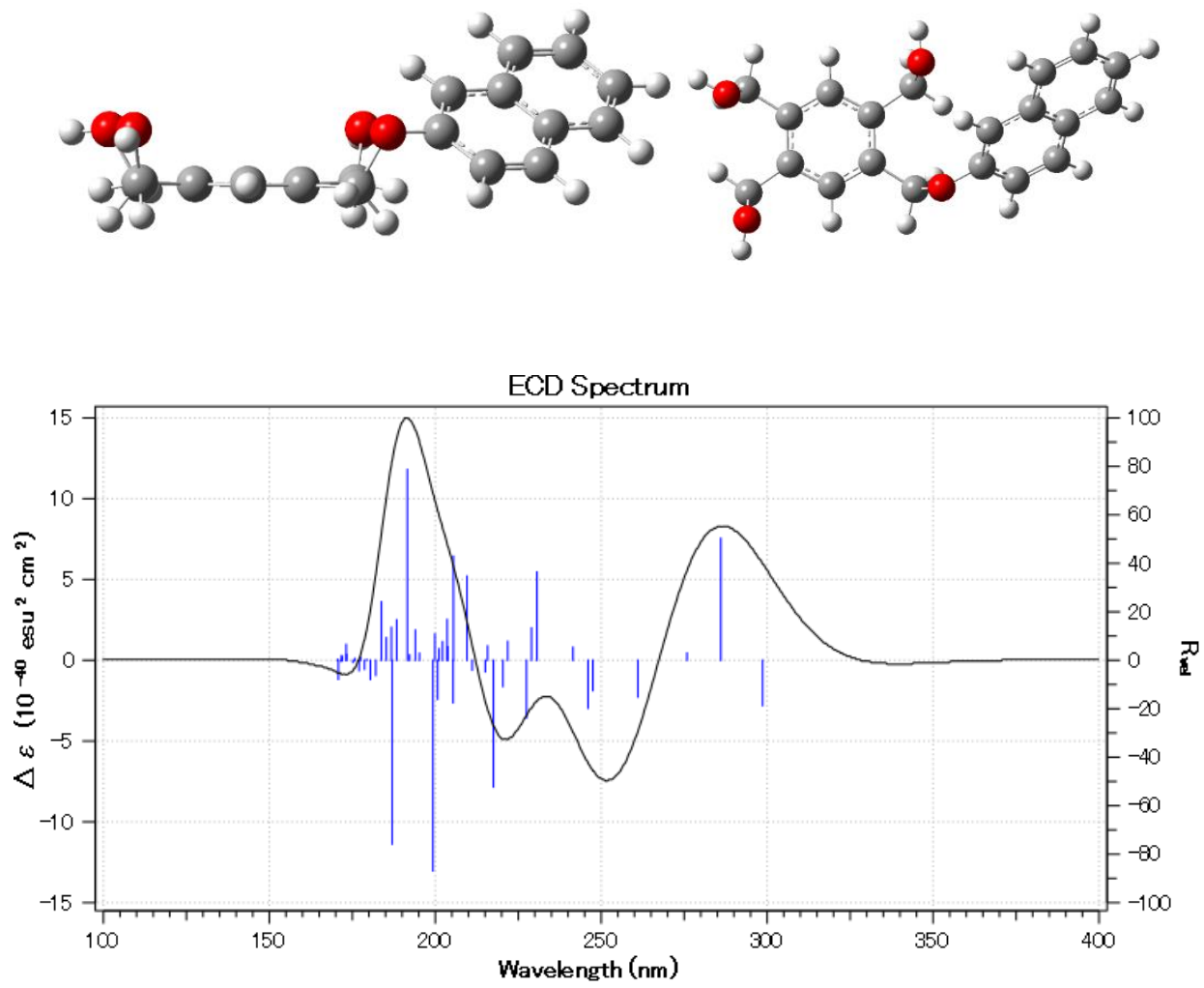

Figure S28. Structure and simulated CD spectrum of part 2 in syn-2 conformation. 

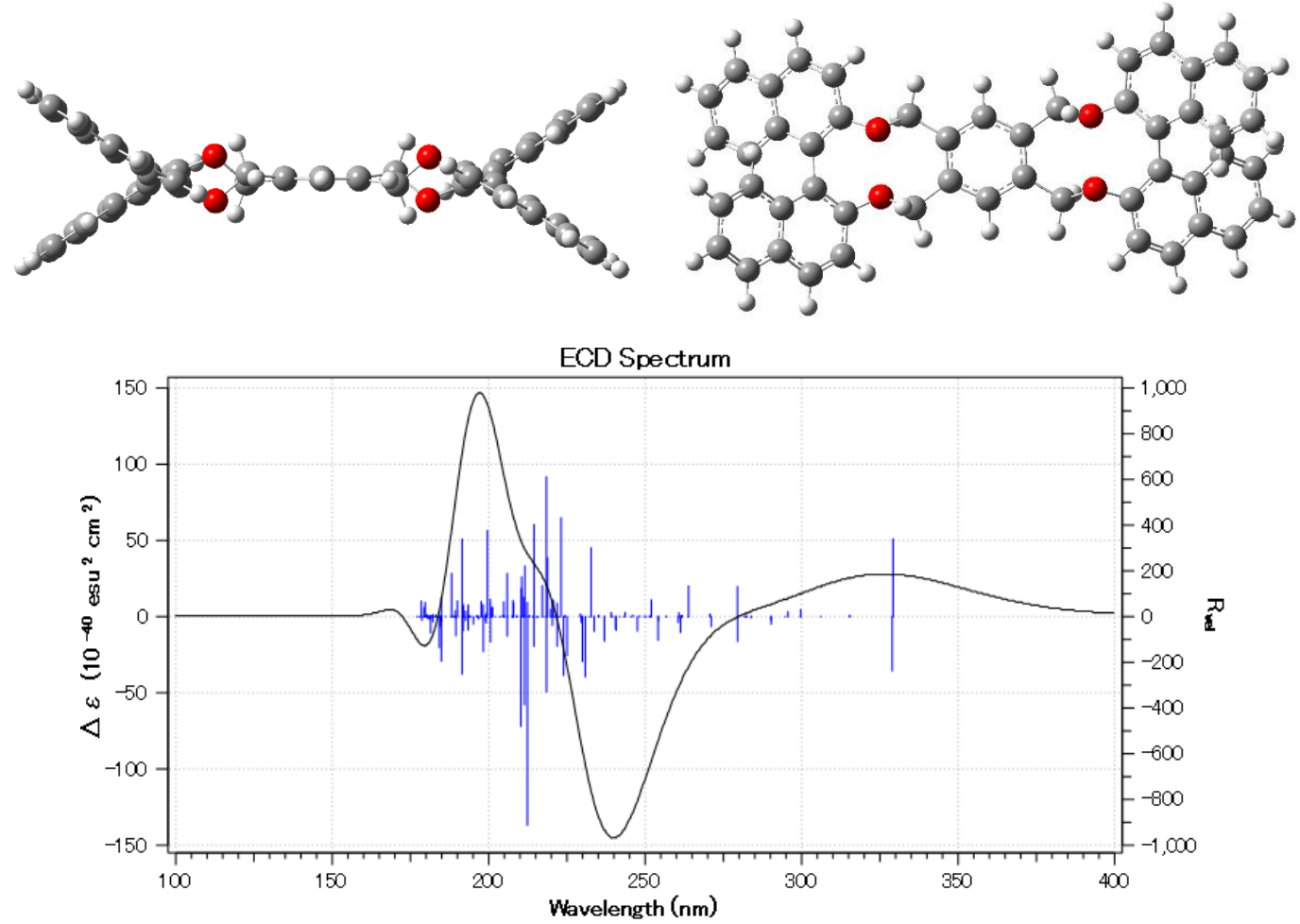

Figure S29. Structure and simulated CD spectrum of flat-1 conformation.
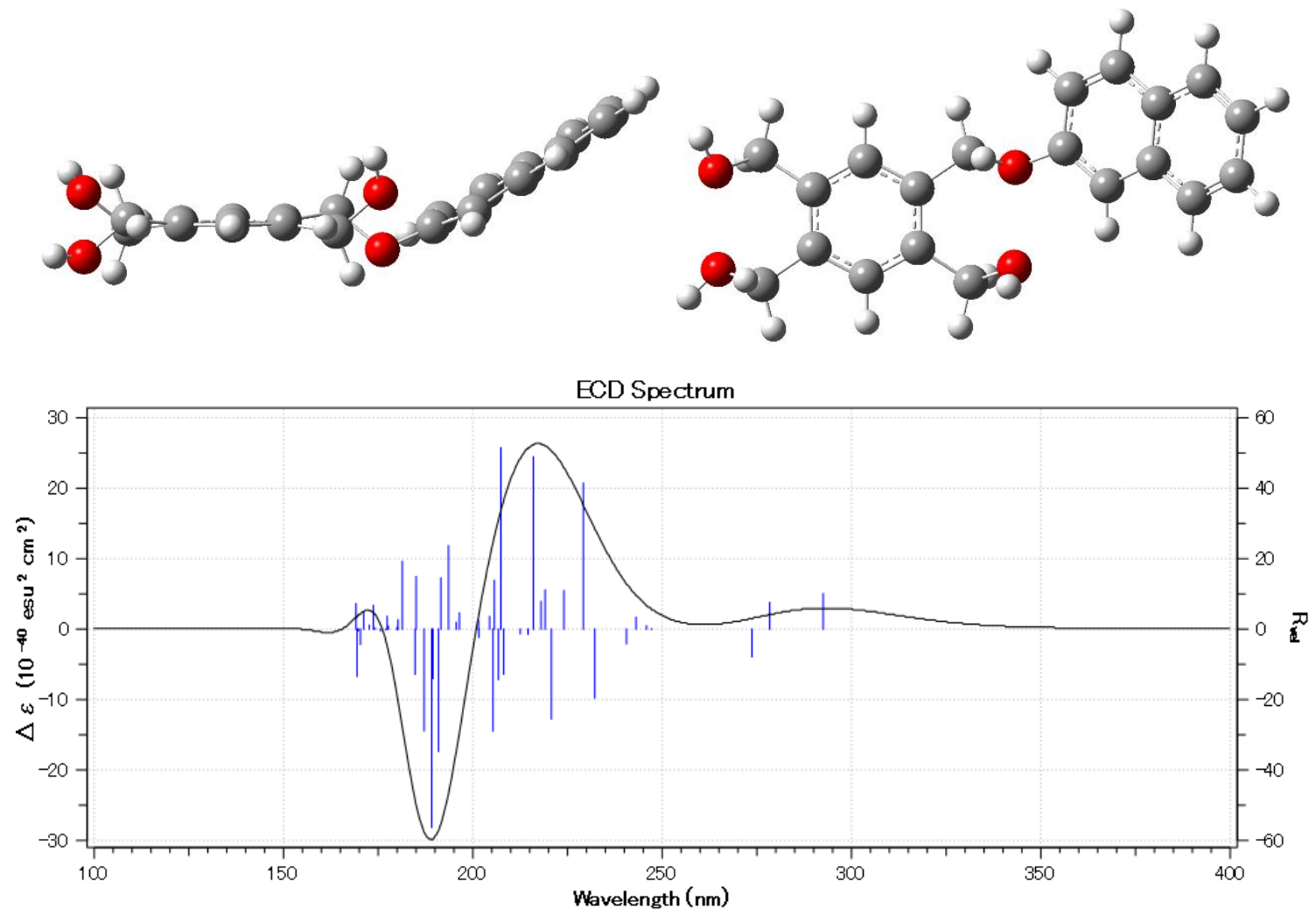

Figure S30. Structure and simulated CD spectrum of part 1 in flat-1 conformation. 
BBD_ANTI1_PART1_TDDFT.LOG

SCF Done: $\quad E(R B 3 L Y P)=-1075.04096797 \quad$ A.U. after 14 cycles

\begin{tabular}{|c|c|c|c|c|c|}
\hline \multirow{2}{*}{$\begin{array}{l}\text { Center } \\
\text { Number }\end{array}$} & \multirow{2}{*}{$\begin{array}{l}\text { Atomic } \\
\text { Number }\end{array}$} & \multirow{2}{*}{$\begin{array}{l}\text { Atomic } \\
\text { Type }\end{array}$} & \multicolumn{3}{|c|}{ Coordinates (Angstroms) } \\
\hline & & & $\mathrm{X}$ & Y & Z \\
\hline 1 & 6 & 0 & 3.581036 & 0.128212 & -0.190064 \\
\hline 2 & 6 & 0 & 3.472874 & -1.245681 & 0.210707 \\
\hline 3 & 6 & 0 & 2.482781 & -1.605725 & 1.156653 \\
\hline 4 & 6 & 0 & 1.624558 & -0.667396 & 1.676914 \\
\hline 5 & 6 & 0 & 1.730348 & 0.688132 & 1.282314 \\
\hline 6 & 6 & 0 & 4.550510 & 0.456864 & -1.180970 \\
\hline 7 & 6 & 0 & 5.373670 & -0.506585 & -1.719303 \\
\hline 8 & 6 & 0 & 5.279290 & -1.855638 & -1.300560 \\
\hline 9 & 6 & 0 & 4.343961 & -2.212287 & -0.358789 \\
\hline 10 & 8 & 0 & 0.918794 & 1.667034 & 1.807250 \\
\hline 11 & 6 & 0 & -0.641984 & 2.754993 & -0.478273 \\
\hline 12 & 6 & 0 & -0.413827 & 1.341886 & 2.205179 \\
\hline 13 & 6 & 0 & -1.314126 & 0.845254 & 1.088037 \\
\hline 14 & 6 & 0 & -1.450593 & 1.526062 & -0.135702 \\
\hline 15 & 6 & 0 & -2.087643 & -0.297155 & 1.309267 \\
\hline 16 & 6 & 0 & -2.989960 & -0.794442 & 0.365391 \\
\hline 17 & 6 & 0 & -3.124376 & -0.118468 & -0.861251 \\
\hline 18 & 6 & 0 & -2.351692 & 1.025394 & -1.079288 \\
\hline 19 & 6 & 0 & -4.089508 & -0.563416 & -1.934570 \\
\hline 20 & 6 & 0 & -3.732388 & -2.081806 & 0.676330 \\
\hline 21 & 1 & 0 & 2.403163 & -2.644726 & 1.466381 \\
\hline 22 & 1 & 0 & 0.872612 & -0.966550 & 2.398273 \\
\hline 23 & 1 & 0 & 4.631678 & 1.483811 & -1.517066 \\
\hline 24 & 1 & 0 & 6.102469 & -0.228784 & -2.475191 \\
\hline 25 & 1 & 0 & 5.939072 & -2.603103 & -1.731099 \\
\hline 26 & 1 & 0 & 4.250884 & -3.246826 & -0.037063 \\
\hline 27 & 1 & 0 & -0.491542 & 3.390317 & 0.401215 \\
\hline 28 & 1 & 0 & -1.171553 & 3.342888 & -1.238011 \\
\hline 29 & 1 & 0 & -0.416599 & 0.619999 & 3.031111 \\
\hline 30 & 1 & 0 & -0.794598 & 2.285224 & 2.609975 \\
\hline 31 & 1 & 0 & -1.982910 & -0.821739 & 2.256677 \\
\hline 32 & 1 & 0 & -2.456426 & 1.549978 & -2.026698 \\
\hline
\end{tabular}




\begin{tabular}{rrrrrr}
33 & 1 & 0 & -3.751695 & -0.190860 & -2.909429 \\
34 & 1 & 0 & -4.148693 & -1.655822 & -1.988557 \\
35 & 1 & 0 & -3.524192 & -2.388837 & 1.708647 \\
36 & 1 & 0 & -3.378378 & -2.891106 & 0.029457 \\
37 & 8 & 0 & -5.382959 & -0.030647 & -1.637850 \\
38 & 1 & 0 & -5.836882 & 0.183259 & -2.456262 \\
39 & 8 & 0 & -5.138910 & -2.045295 & 0.420864 \\
40 & 1 & 0 & -5.552328 & -2.828534 & 0.791300 \\
41 & 8 & 0 & 0.627784 & 2.340842 & -0.989222 \\
42 & 1 & 0 & 0.646264 & 2.465198 & -1.940954 \\
43 & 6 & 0 & 2.704528 & 1.106070 & 0.381668 \\
44 & 1 & 0 & 2.777238 & 2.145137 & 0.136815 \\
\hline & 1 & & & &
\end{tabular}


BBD_ANTI1_PART2_TDDFT.LOG

SCF Done: $\quad E(R B 3 L Y P)=-1075.03835588 \quad$ A.U. after 14 cycles

\begin{tabular}{|c|c|c|c|c|c|}
\hline \multirow{2}{*}{$\begin{array}{l}\text { Center } \\
\text { Number }\end{array}$} & \multirow{2}{*}{$\begin{array}{l}\text { Atomic } \\
\text { Number }\end{array}$} & \multirow{2}{*}{$\begin{array}{l}\text { Atomic } \\
\text { Type }\end{array}$} & \multicolumn{3}{|c|}{ Coordinates (Angstroms) } \\
\hline & & & $\mathrm{X}$ & Y & Z \\
\hline 1 & 6 & 0 & 6.787727 & -0.488226 & -0.007198 \\
\hline 2 & 6 & 0 & 6.103938 & -1.556653 & -0.633083 \\
\hline 3 & 6 & 0 & 4.753679 & -1.473818 & -0.890404 \\
\hline 4 & 6 & 0 & 4.006588 & -0.315101 & -0.536289 \\
\hline 5 & 6 & 0 & 4.699798 & 0.756386 & 0.123462 \\
\hline 6 & 6 & 0 & 6.095433 & 0.640581 & 0.364171 \\
\hline 7 & 6 & 0 & 1.932984 & 0.931310 & -0.330286 \\
\hline 8 & 6 & 0 & 2.617552 & 1.986510 & 0.319166 \\
\hline 9 & 6 & 0 & 3.971551 & 1.901869 & 0.534064 \\
\hline 10 & 8 & 0 & 0.581112 & 1.028076 & -0.561872 \\
\hline 11 & 6 & 0 & -0.254484 & 1.191585 & 0.601319 \\
\hline 12 & 6 & 0 & -0.574599 & -1.769428 & 1.217576 \\
\hline 13 & 6 & 0 & -1.687775 & -0.929172 & 0.617577 \\
\hline 14 & 6 & 0 & -1.550686 & 0.449938 & 0.374843 \\
\hline 15 & 6 & 0 & -2.919099 & -1.536273 & 0.357501 \\
\hline 16 & 6 & 0 & -4.020522 & -0.832345 & -0.136183 \\
\hline 17 & 6 & 0 & -3.884408 & 0.545820 & -0.384762 \\
\hline 18 & 6 & 0 & -2.652790 & 1.151434 & -0.121415 \\
\hline 19 & 6 & 0 & -5.022748 & 1.397396 & -0.895130 \\
\hline 20 & 6 & 0 & -5.292920 & -1.599031 & -0.449846 \\
\hline 21 & 1 & 0 & 7.853106 & -0.565687 & 0.184874 \\
\hline 22 & 1 & 0 & 6.649358 & -2.454325 & -0.911575 \\
\hline 23 & 1 & 0 & 4.241163 & -2.301802 & -1.366085 \\
\hline 24 & 1 & 0 & 6.604797 & 1.464682 & 0.856405 \\
\hline 25 & 1 & 0 & 2.059564 & 2.866673 & 0.624144 \\
\hline 26 & 1 & 0 & 4.500499 & 2.714413 & 1.023873 \\
\hline 27 & 1 & 0 & 0.271577 & 0.813055 & 1.484350 \\
\hline 28 & 1 & 0 & -0.463663 & 2.256836 & 0.758646 \\
\hline 29 & 1 & 0 & -0.883364 & -2.821415 & 1.253326 \\
\hline 30 & 1 & 0 & -0.380718 & -1.462713 & 2.250567 \\
\hline 31 & 1 & 0 & -3.024730 & -2.602341 & 0.547462 \\
\hline 32 & 1 & 0 & -2.547160 & 2.217502 & -0.311375 \\
\hline
\end{tabular}




\begin{tabular}{llllll}
33 & 1 & 0 & -4.620172 & 2.283991 & -1.400252 \\
34 & 1 & 0 & -5.640847 & 0.847036 & -1.612644 \\
35 & 1 & 0 & -5.191338 & -2.638027 & -0.113008 \\
36 & 1 & 0 & -5.459811 & -1.633350 & -1.531374 \\
37 & 8 & 0 & -5.827783 & 1.800658 & 0.215814 \\
38 & 1 & 0 & -6.037810 & 2.734104 & 0.137275 \\
39 & 8 & 0 & -6.494333 & -1.007445 & 0.051685 \\
40 & 1 & 0 & -7.215268 & -1.637472 & -0.018450 \\
41 & 8 & 0 & 0.699717 & -1.625241 & 0.584940 \\
42 & 1 & 0 & 1.341925 & -2.185835 & 1.026419 \\
43 & 6 & 0 & 2.596071 & -0.203104 & -0.778007 \\
44 & 1 & 0 & 2.041453 & -0.961772 & -1.289593 \\
\hline
\end{tabular}


BBD_ANTI2_PART1_TDDFT.LOG

SCF Done: $\quad E(R B 3 L Y P)=-1075.04213545 \quad$ A.U. after 14 cycles

\begin{tabular}{|c|c|c|c|c|c|}
\hline \multirow{2}{*}{$\begin{array}{l}\text { Center } \\
\text { Number }\end{array}$} & \multirow{2}{*}{$\begin{array}{l}\text { Atomic } \\
\text { Number }\end{array}$} & \multirow{2}{*}{$\begin{array}{l}\text { Atomic } \\
\text { Type }\end{array}$} & \multicolumn{3}{|c|}{ Coordinates (Angstroms) } \\
\hline & & & $\mathrm{X}$ & $\mathrm{Y}$ & Z \\
\hline 1 & 6 & 0 & 3.321257 & 0.008419 & 0.095999 \\
\hline 2 & 6 & 0 & 3.241097 & -1.314486 & -0.447919 \\
\hline 3 & 6 & 0 & 2.252217 & -2.202936 & 0.050448 \\
\hline 4 & 6 & 0 & 1.377422 & -1.795458 & 1.024393 \\
\hline 5 & 6 & 0 & 1.448109 & -0.484228 & 1.562744 \\
\hline 6 & 6 & 0 & 4.323981 & 0.880370 & -0.413420 \\
\hline 7 & 6 & 0 & 5.192408 & 0.468774 & -1.399509 \\
\hline 8 & 6 & 0 & 5.108834 & -0.839218 & -1.933684 \\
\hline 9 & 6 & 0 & 4.151047 & -1.707978 & -1.464309 \\
\hline 10 & 8 & 0 & 0.560071 & -0.234888 & 2.591413 \\
\hline 11 & 6 & 0 & -0.401824 & 2.906378 & 0.234781 \\
\hline 12 & 6 & 0 & -0.427531 & 0.806936 & 2.462293 \\
\hline 13 & 6 & 0 & -1.274801 & 0.695701 & 1.210168 \\
\hline 14 & 6 & 0 & -1.257290 & 1.656067 & 0.180675 \\
\hline 15 & 6 & 0 & -2.103387 & -0.420200 & 1.069874 \\
\hline 16 & 6 & 0 & -2.916109 & -0.625263 & -0.047670 \\
\hline 17 & 6 & 0 & -2.900180 & 0.334221 & -1.078011 \\
\hline 18 & 6 & 0 & -2.070803 & 1.450563 & -0.937293 \\
\hline 19 & 6 & 0 & -3.736100 & 0.206095 & -2.336124 \\
\hline 20 & 6 & 0 & -3.783091 & -1.868229 & -0.085547 \\
\hline 21 & 1 & 0 & 2.193197 & -3.208355 & -0.355800 \\
\hline 22 & 1 & 0 & 0.615601 & -2.459280 & 1.417274 \\
\hline 23 & 1 & 0 & 4.398117 & 1.884893 & -0.013230 \\
\hline 24 & 1 & 0 & 5.948012 & 1.154091 & -1.772457 \\
\hline 25 & 1 & 0 & 5.799172 & -1.151779 & -2.711421 \\
\hline 26 & 1 & 0 & 4.076539 & -2.715233 & -1.865684 \\
\hline 27 & 1 & 0 & -0.579504 & 3.471519 & 1.156458 \\
\hline 28 & 1 & 0 & -0.661304 & 3.557069 & -0.606619 \\
\hline 29 & 1 & 0 & -1.056943 & 0.663834 & 3.345390 \\
\hline 30 & 1 & 0 & 0.041498 & 1.787601 & 2.548629 \\
\hline 31 & 1 & 0 & -2.116307 & -1.161961 & 1.865719 \\
\hline 32 & 1 & 0 & -2.057883 & 2.192323 & -1.733138 \\
\hline
\end{tabular}




\begin{tabular}{rrrrrr}
33 & 1 & 0 & -3.451541 & 0.995291 & -3.039599 \\
34 & 1 & 0 & -3.565332 & -0.755833 & -2.832083 \\
35 & 1 & 0 & -3.171515 & -2.749137 & 0.130031 \\
36 & 1 & 0 & -4.237609 & -2.015776 & -1.065745 \\
37 & 8 & 0 & -5.128251 & 0.366790 & -2.051535 \\
38 & 1 & 0 & -5.612475 & 0.478193 & -2.872946 \\
39 & 8 & 0 & -4.781616 & -1.907373 & 0.937349 \\
40 & 1 & 0 & -5.337755 & -2.679914 & 0.812889 \\
41 & 8 & 0 & 0.987592 & 2.588679 & 0.118643 \\
42 & 1 & 0 & 1.489863 & 3.394520 & -0.022579 \\
43 & 6 & 0 & 2.410545 & 0.415424 & 1.130439 \\
44 & 1 & 0 & 2.448987 & 1.386578 & 1.577968 \\
\hline & 1 & & & &
\end{tabular}


BBD_ANTI2_PART2_TDDFT.LOG

SCF Done: $\quad E(R B 3 L Y P)=-1075.04107454 \quad$ A.U. after 14 cycles

\begin{tabular}{|c|c|c|c|c|c|}
\hline \multirow{2}{*}{$\begin{array}{l}\text { Center } \\
\text { Number }\end{array}$} & \multirow{2}{*}{$\begin{array}{l}\text { Atomic } \\
\text { Number }\end{array}$} & \multirow{2}{*}{$\begin{array}{l}\text { Atomic } \\
\text { Type }\end{array}$} & \multicolumn{3}{|c|}{ Coordinates (Angstroms) } \\
\hline & & & $\mathrm{X}$ & Y & Z \\
\hline 1 & 6 & 0 & -5.186650 & -1.209185 & 0.828356 \\
\hline 2 & 6 & 0 & -4.854094 & 1.772577 & 0.221210 \\
\hline 3 & 6 & 0 & -3.717176 & 0.775110 & 0.118582 \\
\hline 4 & 6 & 0 & -3.870793 & -0.598144 & 0.388839 \\
\hline 5 & 6 & 0 & -2.460789 & 1.243139 & -0.273735 \\
\hline 6 & 6 & 0 & -1.349221 & 0.408024 & -0.409653 \\
\hline 7 & 6 & 0 & -1.500853 & -0.965466 & -0.139476 \\
\hline 8 & 6 & 0 & -2.758233 & -1.433377 & 0.252881 \\
\hline 9 & 6 & 0 & 6.300488 & 1.065636 & -0.229090 \\
\hline 10 & 6 & 0 & 5.544165 & 1.847300 & 0.674730 \\
\hline 11 & 6 & 0 & 4.278373 & 1.457480 & 1.052799 \\
\hline 12 & 6 & 0 & 3.699190 & 0.261447 & 0.545276 \\
\hline 13 & 6 & 0 & 4.467098 & -0.527657 & -0.374179 \\
\hline 14 & 6 & 0 & 5.770490 & -0.096743 & -0.740999 \\
\hline 15 & 6 & 0 & 1.879883 & -1.339133 & 0.371108 \\
\hline 16 & 6 & 0 & 2.643849 & -2.125875 & -0.528151 \\
\hline 17 & 6 & 0 & 3.905651 & -1.723590 & -0.892017 \\
\hline 18 & 8 & 0 & 0.627254 & -1.749534 & 0.761431 \\
\hline 19 & 6 & 0 & -0.363419 & -1.959945 & -0.263100 \\
\hline 20 & 6 & 0 & -0.032362 & 1.029733 & -0.830861 \\
\hline 21 & 1 & 0 & -5.592692 & -0.693153 & 1.705444 \\
\hline 22 & 1 & 0 & -5.022769 & -2.255146 & 1.107267 \\
\hline 23 & 1 & 0 & -4.539395 & 2.626846 & 0.827583 \\
\hline 24 & 1 & 0 & -5.733252 & 1.337626 & 0.697702 \\
\hline 25 & 1 & 0 & -2.342851 & 2.304382 & -0.482539 \\
\hline 26 & 1 & 0 & -2.876170 & -2.494619 & 0.461685 \\
\hline 27 & 1 & 0 & 7.298437 & 1.384913 & -0.517751 \\
\hline 28 & 1 & 0 & 5.965911 & 2.764911 & 1.074698 \\
\hline 29 & 1 & 0 & 3.705223 & 2.063335 & 1.744907 \\
\hline 30 & 1 & 0 & 6.342185 & -0.705175 & -1.436606 \\
\hline 31 & 1 & 0 & 2.225805 & -3.054496 & -0.903827 \\
\hline 32 & 1 & 0 & 4.495450 & -2.327710 & -1.576325 \\
\hline
\end{tabular}




\begin{tabular}{rrrrrr}
33 & 1 & 0 & -0.756237 & -2.974043 & -0.136685 \\
34 & 1 & 0 & 0.105710 & -1.908290 & -1.251883 \\
35 & 1 & 0 & -0.184247 & 1.640525 & -1.725491 \\
36 & 1 & 0 & 0.714333 & 0.272737 & -1.072832 \\
37 & 6 & 0 & 2.380450 & -0.162096 & 0.909624 \\
38 & 1 & 0 & 1.769359 & 0.400685 & 1.583971 \\
39 & 8 & 0 & -6.145061 & -1.193419 & -0.232823 \\
40 & 1 & 0 & -6.924226 & -1.687914 & 0.031707 \\
41 & 8 & 0 & -5.209981 & 2.373181 & -1.026796 \\
42 & 1 & 0 & -5.931215 & 2.991935 & -0.890536 \\
43 & 8 & 0 & 0.494094 & 1.963965 & 0.115159 \\
44 & 1 & 0 & 0.493912 & 2.843700 & -0.269115 \\
\hline & 1 & & & &
\end{tabular}


BBD_SYN1_PART1_TDDFT.LOG

SCF Done: $\quad E(R B 3 L Y P)=-1075.04040999 \quad$ A.U. after 14 cycles

\begin{tabular}{|c|c|c|c|c|c|}
\hline \multirow{2}{*}{$\begin{array}{l}\text { Center } \\
\text { Number }\end{array}$} & \multirow{2}{*}{$\begin{array}{l}\text { Atomic } \\
\text { Number }\end{array}$} & \multirow{2}{*}{$\begin{array}{l}\text { Atomic } \\
\text { Type }\end{array}$} & \multicolumn{3}{|c|}{ Coordinates (Angstroms) } \\
\hline & & & $x$ & $\mathrm{Y}$ & Z \\
\hline 1 & 6 & 0 & 5.011988 & 2.212397 & 0.874134 \\
\hline 2 & 6 & 0 & 5.183820 & 0.984103 & 1.555894 \\
\hline 3 & 6 & 0 & 4.419985 & -0.114185 & 1.231778 \\
\hline 4 & 6 & 0 & 3.438183 & -0.050867 & 0.202618 \\
\hline 5 & 6 & 0 & 3.251741 & 1.203251 & -0.469311 \\
\hline 6 & 6 & 0 & 4.062099 & 2.315104 & -0.113928 \\
\hline 7 & 6 & 0 & 1.629977 & -1.002259 & -1.114193 \\
\hline 8 & 6 & 0 & 1.447611 & 0.235203 & -1.775781 \\
\hline 9 & 6 & 0 & 2.245939 & 1.307854 & -1.460715 \\
\hline 10 & 8 & 0 & 0.877865 & -2.114227 & -1.421064 \\
\hline 11 & 6 & 0 & -0.464814 & -1.954936 & -1.877378 \\
\hline 12 & 6 & 0 & -0.637035 & -2.770319 & 1.046531 \\
\hline 13 & 6 & 0 & -1.503956 & -1.683850 & 0.453469 \\
\hline 14 & 6 & 0 & -1.402638 & -1.283150 & -0.892105 \\
\hline 15 & 6 & 0 & -2.428156 & -1.034383 & 1.276557 \\
\hline 16 & 6 & 0 & -3.271732 & -0.018775 & 0.817956 \\
\hline 17 & 6 & 0 & -3.184174 & 0.368280 & -0.532570 \\
\hline 18 & 6 & 0 & -2.244839 & -0.266178 & -1.350211 \\
\hline 19 & 6 & 0 & -4.048343 & 1.457478 & -1.124642 \\
\hline 20 & 6 & 0 & -4.287985 & 0.575238 & 1.775010 \\
\hline 21 & 1 & 0 & 5.624833 & 3.069872 & 1.138317 \\
\hline 22 & 1 & 0 & 5.924197 & 0.908801 & 2.347786 \\
\hline 23 & 1 & 0 & 4.558270 & -1.045360 & 1.769626 \\
\hline 24 & 1 & 0 & 3.907671 & 3.255899 & -0.637463 \\
\hline 25 & 1 & 0 & 0.679118 & 0.339194 & -2.532239 \\
\hline 26 & 1 & 0 & 2.103818 & 2.257184 & -1.969260 \\
\hline 27 & 1 & 0 & -0.498708 & -1.425480 & -2.838430 \\
\hline 28 & 1 & 0 & -0.789356 & -2.982798 & -2.073290 \\
\hline 29 & 1 & 0 & -0.446095 & -3.565319 & 0.319374 \\
\hline 30 & 1 & 0 & -1.145640 & -3.214743 & 1.911479 \\
\hline 31 & 1 & 0 & -2.495463 & -1.341385 & 2.317839 \\
\hline 32 & 1 & 0 & -2.174780 & 0.043553 & -2.390503 \\
\hline
\end{tabular}




\begin{tabular}{rrrrrr}
33 & 1 & 0 & -4.143774 & 1.302911 & -2.206921 \\
34 & 1 & 0 & -5.052462 & 1.446091 & -0.690065 \\
35 & 1 & 0 & -4.116497 & 0.182227 & 2.785568 \\
36 & 1 & 0 & -5.302229 & 0.275493 & 1.489229 \\
37 & 8 & 0 & -3.434210 & 2.724652 & -0.875621 \\
38 & 1 & 0 & -3.536162 & 3.287242 & -1.646789 \\
39 & 8 & 0 & -4.353932 & 2.003713 & 1.778118 \\
40 & 1 & 0 & -5.041898 & 2.291433 & 2.382701 \\
41 & 8 & 0 & 0.604474 & -2.197347 & 1.465169 \\
42 & 1 & 0 & 0.619923 & -2.130676 & 2.422726 \\
43 & 6 & 0 & 2.619736 & -1.172459 & -0.151920 \\
44 & 1 & 0 & 2.747222 & -2.133766 & 0.300336 \\
\hline & 1 & & & &
\end{tabular}


BBD_SYN1_PART2_TDDFT.LOG

SCF Done: $\quad E(R B 3 L Y P)=-1075.03807075 \quad$ A.U. after 14 cycles

\begin{tabular}{|c|c|c|c|c|c|}
\hline \multirow{2}{*}{$\begin{array}{l}\text { Center } \\
\text { Number }\end{array}$} & \multirow{2}{*}{$\begin{array}{l}\text { Atomic } \\
\text { Number }\end{array}$} & \multirow{2}{*}{$\begin{array}{l}\text { Atomic } \\
\text { Type }\end{array}$} & \multicolumn{3}{|c|}{ Coordinates (Angstroms) } \\
\hline & & & $\mathrm{X}$ & Y & Z \\
\hline 1 & 6 & 0 & -5.070523 & -1.660692 & 0.359864 \\
\hline 2 & 6 & 0 & -5.419721 & 1.307702 & -0.197316 \\
\hline 3 & 6 & 0 & -4.089842 & 0.604698 & -0.341867 \\
\hline 4 & 6 & 0 & -3.919788 & -0.762451 & -0.053107 \\
\hline 5 & 6 & 0 & -2.978455 & 1.343458 & -0.757171 \\
\hline 6 & 6 & 0 & -1.709481 & 0.780565 & -0.919195 \\
\hline 7 & 6 & 0 & -1.543795 & -0.590996 & -0.649446 \\
\hline 8 & 6 & 0 & -2.650377 & -1.324902 & -0.213229 \\
\hline 9 & 6 & 0 & 6.714073 & 0.618834 & 0.262766 \\
\hline 10 & 6 & 0 & 5.953953 & 1.664052 & 0.839719 \\
\hline 11 & 6 & 0 & 4.593729 & 1.533202 & 1.010155 \\
\hline 12 & 6 & 0 & 3.912189 & 0.348653 & 0.611697 \\
\hline 13 & 6 & 0 & 4.683408 & -0.698525 & 0.002141 \\
\hline 14 & 6 & 0 & 6.085911 & -0.533305 & -0.148117 \\
\hline 15 & 6 & 0 & 1.900333 & -0.969027 & 0.279496 \\
\hline 16 & 6 & 0 & 2.661461 & -2.000278 & -0.321971 \\
\hline 17 & 6 & 0 & 4.023062 & -1.868962 & -0.449699 \\
\hline 18 & 8 & 0 & 0.540097 & -1.115952 & 0.424209 \\
\hline 19 & 6 & 0 & -0.213042 & -1.293118 & -0.790195 \\
\hline 20 & 6 & 0 & -0.583649 & 1.653655 & -1.440532 \\
\hline 21 & 1 & 0 & -4.687994 & -2.659069 & 0.608882 \\
\hline 22 & 1 & 0 & -5.770746 & -1.791116 & -0.472533 \\
\hline 23 & 1 & 0 & -6.247865 & 0.649038 & -0.475849 \\
\hline 24 & 1 & 0 & -5.445169 & 2.184493 & -0.856798 \\
\hline 25 & 1 & 0 & -3.113485 & 2.401605 & -0.969636 \\
\hline 26 & 1 & 0 & -2.514473 & -2.382167 & 0.003038 \\
\hline 27 & 1 & 0 & 7.786091 & 0.733374 & 0.139205 \\
\hline 28 & 1 & 0 & 6.448121 & 2.579755 & 1.150071 \\
\hline 29 & 1 & 0 & 4.023523 & 2.343030 & 1.449769 \\
\hline 30 & 1 & 0 & 6.655591 & -1.339691 & -0.604188 \\
\hline 31 & 1 & 0 & 2.155644 & -2.899679 & -0.658677 \\
\hline 32 & 1 & 0 & 4.610066 & -2.664000 & -0.902918 \\
\hline
\end{tabular}




\begin{tabular}{rrrrrr}
33 & 1 & 0 & -0.379395 & -2.363625 & -0.965321 \\
34 & 1 & 0 & 0.356892 & -0.895242 & -1.635246 \\
35 & 1 & 0 & -0.922488 & 2.696157 & -1.499434 \\
36 & 1 & 0 & -0.308532 & 1.354726 & -2.457960 \\
37 & 8 & 0 & -5.578446 & 1.726866 & 1.160627 \\
38 & 1 & 0 & -5.987669 & 2.595007 & 1.182279 \\
39 & 8 & 0 & -5.895303 & -1.144790 & 1.407949 \\
40 & 1 & 0 & -6.613827 & -1.757390 & 1.581283 \\
41 & 8 & 0 & 0.647423 & 1.548102 & -0.720657 \\
42 & 1 & 0 & 1.302709 & 2.124828 & -1.120142 \\
43 & 6 & 0 & 2.493951 & 0.188697 & 0.764349 \\
44 & 1 & 0 & 1.882444 & 0.928606 & 1.237099 \\
\hline
\end{tabular}


BBD_SYN2_PART1_TDDFT.LOG

SCF Done: $\quad E(R B 3 L Y P)=-1075.03965759 \quad$ A.U. after 14 cycles

\begin{tabular}{|c|c|c|c|c|c|}
\hline \multirow{2}{*}{$\begin{array}{l}\text { Center } \\
\text { Number }\end{array}$} & \multirow{2}{*}{$\begin{array}{l}\text { Atomic } \\
\text { Number }\end{array}$} & \multirow{2}{*}{$\begin{array}{l}\text { Atomic } \\
\text { Type }\end{array}$} & \multicolumn{3}{|c|}{ Coordinates (Angstroms) } \\
\hline & & & $x$ & $\mathrm{Y}$ & Z \\
\hline 1 & 6 & 0 & -3.135476 & 0.052755 & -0.070611 \\
\hline 2 & 6 & 0 & -2.962891 & -1.275259 & -0.581492 \\
\hline 3 & 6 & 0 & -1.962942 & -1.511807 & -1.560805 \\
\hline 4 & 6 & 0 & -1.170180 & -0.486003 & -2.006961 \\
\hline 5 & 6 & 0 & -1.335366 & 0.830601 & -1.504392 \\
\hline 6 & 6 & 0 & -4.144392 & 0.265569 & 0.909837 \\
\hline 7 & 6 & 0 & -4.932985 & -0.770282 & 1.358577 \\
\hline 8 & 6 & 0 & -4.760493 & -2.079798 & 0.850496 \\
\hline 9 & 6 & 0 & -3.794920 & -2.321240 & -0.100122 \\
\hline 10 & 8 & 0 & -0.529117 & 1.786500 & -2.095122 \\
\hline 11 & 6 & 0 & 0.468580 & 2.445593 & 1.756953 \\
\hline 12 & 6 & 0 & 0.441318 & 2.503889 & -1.306091 \\
\hline 13 & 6 & 0 & 1.355771 & 1.602724 & -0.502439 \\
\hline 14 & 6 & 0 & 1.352553 & 1.555659 & 0.904169 \\
\hline 15 & 6 & 0 & 2.228514 & 0.761323 & -1.198314 \\
\hline 16 & 6 & 0 & 3.070268 & -0.197369 & 0.846910 \\
\hline 17 & 6 & 0 & 3.086300 & -0.137675 & -0.559130 \\
\hline 18 & 6 & 0 & 2.210339 & 0.656661 & 1.543352 \\
\hline 19 & 6 & 0 & 4.001595 & -0.996738 & -1.410528 \\
\hline 20 & 6 & 0 & 3.922079 & -1.160277 & 1.647790 \\
\hline 21 & 1 & 0 & -1.822183 & -2.519827 & -1.940232 \\
\hline 22 & 1 & 0 & -0.397907 & -0.648997 & -2.749346 \\
\hline 23 & 1 & 0 & -4.286408 & 1.264046 & 1.307982 \\
\hline 24 & 1 & 0 & -5.695634 & -0.581773 & 2.108793 \\
\hline 25 & 1 & 0 & -5.390912 & -2.887245 & 1.208804 \\
\hline 26 & 1 & 0 & -3.654014 & -3.319730 & -0.504652 \\
\hline 27 & 1 & 0 & 0.585691 & 3.500523 & 1.486292 \\
\hline 28 & 1 & 0 & 0.757877 & 2.340072 & 2.807579 \\
\hline 29 & 1 & 0 & 1.021336 & 3.046621 & -2.057784 \\
\hline 30 & 1 & 0 & -0.053949 & 3.244648 & -0.676732 \\
\hline 31 & 1 & 0 & 2.228185 & 0.803348 & -2.285578 \\
\hline 32 & 1 & 0 & 2.203549 & 0.607619 & 2.630301 \\
\hline
\end{tabular}




\begin{tabular}{rrrrrr}
33 & 1 & 0 & 3.947210 & -0.659683 & -2.450758 \\
34 & 1 & 0 & 5.044806 & -0.908028 & -1.088518 \\
35 & 1 & 0 & 4.438316 & -0.622515 & 2.447998 \\
36 & 1 & 0 & 4.683579 & -1.638630 & 1.030213 \\
37 & 8 & 0 & 3.163306 & -2.145268 & 2.354159 \\
38 & 1 & 0 & 3.422791 & -2.147573 & 3.278421 \\
39 & 8 & 0 & 3.600851 & -2.369215 & -1.385780 \\
40 & 1 & 0 & 4.252289 & -2.901647 & -1.848105 \\
41 & 8 & 0 & -0.906681 & 2.067600 & 1.653608 \\
42 & 1 & 0 & -1.298085 & 2.039787 & 2.529753 \\
43 & 6 & 0 & -2.305108 & 1.119157 & -0.556588 \\
44 & 1 & 0 & -2.408796 & 2.127176 & -0.213011 \\
\hline & 1 & & & &
\end{tabular}


BBD_SYN2_PART2_TDDFT.LOG

SCF Done: $\quad E(R B 3 L Y P)=-1075.03905541 \quad$ A.U. after 14 cycles

\begin{tabular}{|c|c|c|c|c|c|}
\hline \multirow{2}{*}{$\begin{array}{l}\text { Center } \\
\text { Number }\end{array}$} & \multirow{2}{*}{$\begin{array}{l}\text { Atomic } \\
\text { Number }\end{array}$} & \multirow{2}{*}{$\begin{array}{l}\text { Atomic } \\
\text { Type }\end{array}$} & \multicolumn{3}{|c|}{ Coordinates (Angstroms) } \\
\hline & & & $\mathrm{X}$ & $\mathrm{Y}$ & Z \\
\hline 1 & 6 & 0 & 6.268769 & 1.051758 & 0.073338 \\
\hline 2 & 6 & 0 & 5.434302 & 1.876548 & 0.863680 \\
\hline 3 & 6 & 0 & 4.134748 & 1.509471 & 1.132917 \\
\hline 4 & 6 & 0 & 3.598036 & 0.293959 & 0.624495 \\
\hline 5 & 6 & 0 & 4.445111 & -0.538456 & -0.180777 \\
\hline 6 & 6 & 0 & 5.781234 & -0.129770 & -0.435969 \\
\hline 7 & 6 & 0 & 1.793307 & -1.308284 & 0.351249 \\
\hline 8 & 6 & 0 & 2.633296 & -2.136861 & -0.437051 \\
\hline 9 & 6 & 0 & 3.926750 & -1.754344 & -0.696419 \\
\hline 10 & 8 & 0 & 0.507182 & -1.699952 & 0.643852 \\
\hline 11 & 6 & 0 & -0.393217 & -1.944197 & -0.452806 \\
\hline 12 & 6 & 0 & 0.026662 & 1.009321 & -1.150524 \\
\hline 13 & 6 & 0 & -1.329687 & 0.419663 & -0.823722 \\
\hline 14 & 6 & 0 & -1.521756 & -0.931090 & -0.478255 \\
\hline 15 & 6 & 0 & -2.439457 & 1.269253 & -0.845712 \\
\hline 16 & 6 & 0 & -3.918656 & -0.506229 & -0.159988 \\
\hline 17 & 6 & 0 & -3.729543 & 0.840407 & -0.522726 \\
\hline 18 & 6 & 0 & -2.811841 & -1.359936 & -0.155270 \\
\hline 19 & 6 & 0 & -4.865306 & 1.843450 & -0.590395 \\
\hline 20 & 6 & 0 & -5.260556 & -1.075759 & 0.251254 \\
\hline 21 & 1 & 0 & 7.291675 & 1.353738 & -0.128874 \\
\hline 22 & 1 & 0 & 5.823571 & 2.809566 & 1.262491 \\
\hline 23 & 1 & 0 & 3.500311 & 2.147413 & 1.737642 \\
\hline 24 & 1 & 0 & 6.413319 & -0.770738 & -1.045823 \\
\hline 25 & 1 & 0 & 2.245960 & -3.080125 & -0.807697 \\
\hline 26 & 1 & 0 & 4.574273 & -2.391593 & -1.293127 \\
\hline 27 & 1 & 0 & 0.162308 & -1.945750 & -1.396861 \\
\hline 28 & 1 & 0 & -0.811845 & -2.946293 & -0.314257 \\
\hline 29 & 1 & 0 & -0.031713 & 1.583032 & -2.079755 \\
\hline 30 & 1 & 0 & 0.782646 & 0.235329 & -1.290277 \\
\hline 31 & 1 & 0 & -2.285432 & 2.312056 & -1.115431 \\
\hline 32 & 1 & 0 & -2.964225 & -2.400451 & 0.124045 \\
\hline
\end{tabular}




\begin{tabular}{rrrrrr}
33 & 1 & 0 & -4.500863 & 2.770067 & -1.045594 \\
34 & 1 & 0 & -5.688475 & 1.472180 & -1.210396 \\
35 & 1 & 0 & -5.455047 & -2.001708 & -0.297212 \\
36 & 1 & 0 & -6.077950 & -0.387311 & 0.032138 \\
37 & 8 & 0 & -5.312202 & -1.490344 & 1.618862 \\
38 & 1 & 0 & -5.631506 & -2.394361 & 1.667829 \\
39 & 8 & 0 & -5.349916 & 2.171517 & 0.714375 \\
40 & 1 & 0 & -6.129112 & 2.726852 & 0.636551 \\
41 & 6 & 0 & 2.247317 & -0.109256 & 0.879837 \\
42 & 1 & 0 & 1.577506 & 0.485187 & 1.465406 \\
43 & 8 & 0 & 0.475332 & 1.976953 & -0.198009 \\
44 & 1 & 0 & 0.524359 & 2.839612 & -0.616358 \\
\hline & 1 & & & &
\end{tabular}


BBD_FLAT_PART1_TDDFT.LOG

SCF Done: $\quad E(R B 3 L Y P)=-1075.03845594 \quad$ A.U. after 14 cycles

\begin{tabular}{|c|c|c|c|c|c|}
\hline \multirow{2}{*}{$\begin{array}{l}\text { Center } \\
\text { Number }\end{array}$} & \multirow{2}{*}{$\begin{array}{l}\text { Atomic } \\
\text { Number }\end{array}$} & \multirow{2}{*}{$\begin{array}{l}\text { Atomic } \\
\text { Type }\end{array}$} & \multicolumn{3}{|c|}{ Coordinates (Angstroms) } \\
\hline & & & $\mathrm{X}$ & Y & Z \\
\hline 1 & 6 & 0 & -6.752759 & -0.169677 & 1.036980 \\
\hline 2 & 6 & 0 & -6.289405 & 1.160883 & 0.934728 \\
\hline 3 & 6 & 0 & -5.065509 & 1.440810 & 0.368882 \\
\hline 4 & 6 & 0 & -4.218518 & 0.404319 & -0.120176 \\
\hline 5 & 6 & 0 & -4.678614 & -0.945585 & 0.029523 \\
\hline 6 & 6 & 0 & -5.956627 & -1.199464 & 0.594068 \\
\hline 7 & 6 & 0 & -2.087613 & -0.413418 & -0.936600 \\
\hline 8 & 6 & 0 & -2.564353 & -1.746244 & -0.824067 \\
\hline 9 & 6 & 0 & -3.832695 & -2.007803 & -0.378183 \\
\hline 10 & 8 & 0 & -0.755327 & -0.243982 & -1.271967 \\
\hline 11 & 6 & 0 & 0.076377 & -0.798294 & -0.228881 \\
\hline 12 & 6 & 0 & 0.773447 & 2.187339 & -0.557361 \\
\hline 13 & 6 & 0 & 1.779264 & 1.118730 & -0.216706 \\
\hline 14 & 6 & 0 & 1.480751 & -0.253200 & -0.213206 \\
\hline 15 & 6 & 0 & 3.108694 & 1.509418 & -0.032855 \\
\hline 16 & 6 & 0 & 4.157100 & 0.602196 & 0.144946 \\
\hline 17 & 6 & 0 & 3.861400 & -0.770252 & 0.128652 \\
\hline 18 & 6 & 0 & 2.530564 & -1.160682 & -0.045302 \\
\hline 19 & 6 & 0 & 4.914495 & -1.847547 & 0.136764 \\
\hline 20 & 6 & 0 & 5.514196 & 1.155975 & 0.493165 \\
\hline 21 & 1 & 0 & -7.725551 & -0.375479 & 1.474927 \\
\hline 22 & 1 & 0 & -6.904283 & 1.974730 & 1.310031 \\
\hline 23 & 1 & 0 & -4.729505 & 2.468245 & 0.312014 \\
\hline 24 & 1 & 0 & -6.285881 & -2.231576 & 0.682329 \\
\hline 25 & 1 & 0 & -1.902973 & -2.555205 & -1.115086 \\
\hline 26 & 1 & 0 & -4.194374 & -3.030760 & -0.308916 \\
\hline 27 & 1 & 0 & -0.393396 & -0.576250 & 0.736205 \\
\hline 28 & 1 & 0 & 0.120963 & -1.888954 & -0.335509 \\
\hline 29 & 1 & 0 & 0.541053 & 2.117812 & -1.626259 \\
\hline 30 & 1 & 0 & 1.225987 & 3.170020 & -0.377237 \\
\hline 31 & 1 & 0 & 3.338718 & 2.571790 & -0.027902 \\
\hline 32 & 1 & 0 & 2.300539 & -2.223053 & -0.050255 \\
\hline
\end{tabular}




\begin{tabular}{llllll}
33 & 1 & 0 & 4.422557 & -2.822989 & 0.233759 \\
34 & 1 & 0 & 5.435902 & -1.831120 & -0.827211 \\
35 & 1 & 0 & 5.694956 & 0.987031 & 1.560951 \\
36 & 1 & 0 & 5.509008 & 2.239398 & 0.322673 \\
37 & 8 & 0 & 5.888999 & -1.697753 & 1.172526 \\
38 & 1 & 0 & 5.978221 & -2.525392 & 1.650704 \\
39 & 8 & 0 & 6.588447 & 0.561173 & -0.239703 \\
40 & 1 & 0 & 7.394589 & 1.059930 & -0.088124 \\
41 & 8 & 0 & -0.452039 & 2.083658 & 0.172250 \\
42 & 1 & 0 & -0.356767 & 2.519508 & 1.022284 \\
43 & 6 & 0 & -2.916137 & 0.674446 & -0.692795 \\
44 & 1 & 0 & -2.634762 & 1.675836 & -0.943688 \\
\hline
\end{tabular}




\section{References}

(1) Frisch, M. J.; Trucks, G. W.; Schlegel, H. B.; Scuseria, G. E.; Robb, M. A.; Cheeseman, J. R.; Scalmani, G.; Barone, V.; Petersson, G. A.; Nakatsuji, H.; Li, X.; Caricato, M.; Marenich, A. v.; Bloino, J.; Janesko, B. G.; Gomperts, R.; Mennucci, B.; Hratchian, H. P.; Ortiz, J. v.; Izmaylov, A. F.; et al. Gaussian 16, Revision C.01; Gaussian, Inc.: Wallingford CT, 2016.

(2) Becke, A. D. Density-Fnnctional Exchange-Energy Approximation with Correct Asymptotic Behavior. Phys. Rev. A 1988, 38, 3098-3100.

(3) Becke, A. D. Density-Functional Thermochemistry. III. The Role of Exact Exchange. J. Chem. Phys. 1993, 98, 5648-5652.

(4) Lee, C.; Yang, W.; Parr, R. G. Development of the Colle-Salvetti Correlation-Energy Formula into a Functional of the Electron Density. Phys. Rev. B 1988, 37, 785-789.

(5) Ditchfield, R.; Hehre, W. J.; Pople, J. A. Self-Consistent Molecular-Orbital Methods. IX. An Extended Gaussian-Type Basis for Molecular-Orbital Studies of Organic Molecules. J. Chem. Phys. 1971, 54, 724-728.

(6) Hehre, W. J.; Ditchfield, R.; Pople, J. A. Self-Consistent Molecular Orbital Methods. XII. Further Extensions of Gaussian-Type Basis Sets for Use in Molecular Orbital Studies of Organic Molecules. J. Chem. Phys. 1972, 56, 2257-2261.

(7) Hariharan, P. C.; Pople, J. A. Accuracy of AHn Equilibrium Geometries by Single Determinant Molecular Orbital Theory. Mol. Phys. 1974, 27, 209-214.

(8) Gordon, M. S. The Isomers of Silacyclopropane. Chem. Phys. Lett. 1980, 76, 163-168.

(9) Hariharan, P. C.; Pople, J. A. The Influence of Polarization Functions on Molecular Orbital Hydrogenation Energies. Theoret. chim. Acta 1973, 28, 213-222.

(10) Soe, W. H.; Shirai, Y.; Durand, C.; Yonamine, Y.; Minami, K.; Bouju, X.; Kolmer, M.; Ariga, K.; Joachim, C.; Nakanishi, W. Conformation Manipulation and Motion of a Double Paddle Molecule on an Au(111) Surface. ACS Nano 2017, 11, 10357-10365.

(11) Bauernschmitt, R.; Ahlrichs, R. Treatment of Electronic Excitations within the Adiabatic Approximation of Time Dependent Density Functional Theory. Chem. Phys. Lett. 1996, 256, 454-464. 